\title{
, \\ On the Limits of Across-the-Board Movement: Distributed Extraction Coordinations
}

\author{
Željko Bošković
}

check for

updates

Citation: Bošković, Ž. On the Limits of Across-the-Board Movement: Distributed Extraction Coordinations. Philosophies 2022, 7, 10. https:// doi.org/10.3390/philosophies7010010

Academic Editor: Peter Kosta

Received: 8 August 2021

Accepted: 26 November 2021

Published: 22 January 2022

Publisher's Note: MDPI stays neutral with regard to jurisdictional claims in published maps and institutional affiliations.

Copyright: (C) 2022 by the author. Licensee MDPI, Basel, Switzerland. This article is an open access article distributed under the terms and conditions of the Creative Commons Attribution (CC BY) license (https:// creativecommons.org/licenses/by/ $4.0 /)$.
Department of Linguistics, University of Connecticut, Storrs, CT 06269-1145, USA; zeljko.boskovic@uconn.edu

\begin{abstract}
The paper examines distributed extraction coordinations, in which different elements move out of conjuncts of a single coordination, as in Which book and which magazine did Mary buy and Amy read respectively, from a crosslinguistic perspective. A number of properties of such coordinations are discussed, which includes showing that they are also subject to the ATB requirement, which will shed light on the nature of the ATB phenomenon itself. It is also shown that there is a rather strong restriction on distributed extractions which confines such extractions to one context and completely excludes one type of movement, in particular head-movement, from participating in them. The higher coordination is shown to be formed during the derivation and to be semantically expletive. Distributed extraction constructions are also shown to have consequences for the proper analysis of a number of phenomena, including subject-oriented anaphors, right node raising, toughconstructions, agreement, and clausal structure. Regarding subject-oriented anaphors, the paper teases apart different approaches to subject-oriented anaphors based on constructions where different elements fill SpecvP and SpecTP (the latter undergoes agreement with $\mathrm{T}$ and the former binds subjectoriented anaphors).
\end{abstract}

Keywords: across-the-board movement; clausal structure; coordination; Japanese; sideward merger; Slavic; subject-oriented anaphors

\section{Introduction}

It is well-known that extraction out of conjuncts is disallowed, unless the moving element moves out of each conjunct. This well-known phenomenon is illustrated by (2) and (3). The ban on extraction out of conjuncts, given in (1), is standardly referred to as the Coordinate Structure Constraint (CSC), and the rescuing effect in (3) as across-the-boardmovement (ATB).

(1) Extraction out of conjuncts is disallowed.

(2) ${ }^{*} \mathrm{Who}_{\mathrm{i}}$ did you see [enemies of $\mathrm{t}_{\mathrm{i}}$ ] and John?

(3) Who $\mathrm{i}_{\mathrm{i}}$ did you see [friends of $t_{i}$ ] and [enemies of $t_{i}$ ]?

Both the CSC and the ATB exception were noted in [1]. (4) and (5) give the original formulations of the CSC and the ATB exception. ${ }^{1}$

(4) In a coordinate structure, no conjunct may be moved, nor may any element contained in a conjunct be moved out of that conjunct [1], (pp. 98-99);

(5) There is an important class of rules to which (4) does not apply. These are rule schemata which move a constituent out of all the conjuncts of a coordinate structure [1], (p. 107).

The upshot of (4), (5) is that extraction of $X$ out of a conjunct is unacceptable unless $X$ is extracted out of each conjunct of the coordination.

There is an interesting exception to this well-known pattern that has not received much attention, the most detailed discussions being smaller parts of larger works, in particular [2,7]. The exception concerns examples such as (6). ${ }^{2}$

(6) Which book $\mathrm{i}_{\mathrm{i}}$ and which magazine $\mathrm{j}_{\mathrm{j}}$ did [John buy $\mathrm{t}_{\mathrm{i}}$ ] and [Bill read $\mathrm{t}_{\mathrm{j}}$ ] respectively? 
Postal [2] provides strong evidence that which book and which magazine undergo separate extractions out of the conjuncts in (6), and [7] argues that such cases involve coordination-formation that takes place after (more precisely, through) movement. ${ }^{3}$ These examples violate the CSC ban in (1). They also do not fit the ATB pattern in (3): it is not the case that the moving element is extracted out of each conjunct in (6). (6) in fact appears to involve two separate extractions, of two different elements, out of the conjuncts. One may then expect (6) to be even worse than (2).

The goal of this paper is to examine this kind of constructions, which for ease of exposition I will refer to as distributed extractions. Additional cases of distributed extractions will be discussed in the effort to examine restrictions on distributed extractions. Evidence will be provided that all these cases involve coordination formation after movement (I will refer to such coordination as late coordination) and the precise timing of (and the operations involved in) this late coordination formation will be discussed. It will also be argued that distributed extractions are actually subject to the ATB requirement, which will shed light on the nature of the ATB phenomenon itself. It will also be shown that there is a rather strong restriction on distributed extractions which confines such extractions to one context and completely excludes one type of movement, in particular head-movement, from participating in such extractions.

It should, however, be noted that one of the main goals of the paper is descriptive, namely to broaden the scope of the phenomenon empirically. There has been very little discussion of the phenomenon in question outside of English (and outside of constructions such as (6)). In this respect, the paper will bring in additional languages, with constructions which are quite different from (6). The restrictions on distributed extraction coordination established below should also be looked at from this perspective: their goal is to empirically broaden the scope of the phenomenon in question-in this respect the restrictions are actually more important than their deductions. At any rate, one of the main goals of this paper is to prompt further crosslinguistic investigation of the phenomenon in question as well as several related properties of coordination which are discussed below.

Going beyond coordination, the coordination data discussed in this paper will be shown to have consequences for a number of coordination independent mechanisms in that they shed light on how the mechanisms in question should be analyzed. To mention just some of them here: subject-oriented anaphors, right node raising, tough-constructions, and agreement. Regarding subject-oriented anaphors, the paper will tease apart different approaches to subject-oriented anaphors based on constructions where different elements fill the SpecvP and the SpecTP position (the latter undergoes agreement with T). The coordination data discussed in the paper will also be shown to have consequences for determining clausal structure more generally.

The paper is organized as follows. In Section 2, I present arguments (mostly from [2], but also new arguments) that (6) involves extraction out of each conjunct. The section will also show that the ATB requirement (more precisely, a reformulated ATB requirement) is operative with such constructions. In Sections 3 and 4, I present additional cases of distributed extractions and show that these additional cases are also subject to the reformulated ATB requirement. The possibility of mixing distributed extraction and traditional ATB in the same sentence is also discussed. Section 5 establishes a new generalization regarding the availability of distributed extractions and Section 6 discusses islandhood of distributed extraction constructions. Sections 7 and 8 examine the exact timing (and the mechanism) of late-coordination formation and explore consequences of distributed extraction coordinations for other phenomena, such as subject-oriented anaphors, right node raising, tough-constructions, agreement, and clausal structure. Section 9 is the conclusion, and Appendix A discusses a related construction (referred to as wh\&wh coordination) that also involves late coordination, outlining the range of possible crosslinguistic variation in the relevant domain. It also discusses the ordering of elements involved in late coordination formation. 


\section{Distributed Coordinations with Wh-Movement in English}

\subsection{Distributed Coordinations Involve Separate Extractions}

In ref [2], the author gives strong evidence that each wh-phrase is separately extracted from the conjuncts in constructions such as (6). A rather strong argument to this effect is provided by the possibility of binding into the individual conjuncts in (7), where which man binds an anaphor in the first conjunct and which woman binds an anaphor in the second conjunct.

(7) [Which man $]_{i}$ and [which woman $]_{j}$ did respectively the doctor talk to $t_{i}$ about himself $f_{i}$, and the lawyer talk to $t_{j}$ about herself $f_{j}[2],(p .161)$

Such licensing is also possible with parasitic gaps, as shown by (8), where the first wh-phrase licenses a parasitic gap in the first conjunct and the second wh-phrase licenses it in the second conjunct.

(8) [Which secretary $]_{1}$ and [which programmer $]_{2}$ did Jerome respectively fire $t_{1}$ after finding $t_{1}$ drunk and hire $t_{2}$ after finding $t_{2}$ sober? [2], (p. 136)

Another argument comes from cases where the extracted elements contain an anaphor: the anaphor can be bound within the first conjunct or within the second conjunct, as in (9) (for a somewhat different reconstruction effect, see (83)). ${ }^{4}$ The binding relations can also be combined, as in (10) (for additional binding data, see Section 7.3).

(9) a. (?)[Which painting] and [which book about herself $f_{i}$ ] did John buy and Mary $y_{i}$ sell respectively?

b. (?)[Which book about herself $\mathrm{f}_{\mathrm{i}}$ ] and [which painting] did Mary $\mathrm{y}_{\mathrm{i}}$ buy and John sell respectively?

(10) [Which book about himself $\mathrm{j}_{\mathrm{j}}$ ] and [which picture of herself $\left.\mathrm{f}_{\mathrm{i}}\right]_{\text {did }} \mathrm{John}_{\mathrm{j}}$ buy and Mary $\mathrm{i}_{\mathrm{i}}$ sell respectively?

Also relevant are examples such as (11). It is well-known that the indirect object in double object constructions cannot undergo wh-movement. This constraint is also operative with distributed coordinations, as shown by (11b).

(11) a. [Which nurse $]_{1}$ and [which hostess $]_{2}$ did Ernest sell cocaine to $t_{1}$, and George sell heroin to $t_{2}$, respectively?

b. ${ }^{*}[\text { Which nurse }]_{1}$ and [which hostess $]_{2}$ did Ernest sell $t_{1}$ cocaine and George sell $t_{2}$ heroin, respectively? [2], (p. 135)

\subsection{The ATB Requirement on Distributed Coordinations}

The evidence discussed in the previous section shows that distributed coordination constructions such as (6) involve separate wh-movements from each conjunct. As such, they do not fit the traditional ATB-exception-to-the-CSC schema, where the CSC is voided if the moving element moves out of each conjunct. Notice, however, that examples such as (6) do actually involve movement out of each conjunct, the difference between (3) and (6) being that in (3) it is the same element that moves out of each conjunct while in (6) different elements move out of the conjuncts.

Interestingly, it turns out that the ATB requirement holds for constructions such as (6) as well. This is shown by the unacceptability of (12), (13), which contrast with (14).

(12) ${ }^{*}$ Which book ${ }_{i}$ and which magazine ${ }_{j}$ did [John buy $t_{i}$ ], [Bill read $t_{j}$ ] and [Mary write a novel] respectively?

(13) *Which book $_{i}$ and which magazine $e_{j}$ did [Mary write a novel], [John buy $t_{1}$ ] and [Bill read $t_{2}$ ] respectively?

(14) Which book ${ }_{i}$, which magazine ${ }_{j}$ and which novel ${ }_{k}$ did [John buy $t_{i}$ ], [Bill read $t_{j}$ ] and [Mary borrow $t_{k}$ ] respectively?

These data indicate that the ATB requirement is at work in the construction under consideration: movement still must take place out of each conjunct. This means that the ATB requirement needs to be reformulated: it is not the case that the moving element must 
move out of each conjunct; rather, movement must take place out of each conjunct. It can be the same element moving out of each conjunct or different elements: as long as there is a gap in each conjunct the ATB requirement is satisfied. I will refer to the cases where different elements move from the conjuncts as non-ATB ATB. ${ }^{5}$

Not only does the ATB requirement hold for distributed coordination constructions but it in fact holds in the same way as with regular ATB constructions. It is well-known that there is an interpretative parallelism requirement on regular ATB. Thus, both gaps must be either subjects or objects (the requirement is actually more detailed than that, it can also affect two internal arguments and concerns thematic prominence-see $[9,10]$ and references therein).

(15) *I wonder who ${ }_{i}\left[t_{i}\right.$ left $]$ and [Mary kissed $\left.t_{i}\right]$.

(16) *I wonder who $o_{i}\left[J o h n\right.$ saw $t_{i}$ ] and [ $t_{i}$ kissed Mary].

Zhang [7], (p. 193) observes the data in (17)-(19), which indicate that the parallelism requirement in question also holds for non-ATB ATB.

(17) [[Which nurse $]_{i}$ and [which hostess $\left.]_{j}\right] t_{i}$ dated Fred and $t_{j}$ married Bob respectively?

(18) [[Which nurse $]_{i}$ and [which hostess $\left.]_{j}\right]$ did Fred date $t_{i}$ and Bob marry $t_{j}$, respectively?

(19) $\left.{ }^{*}\left[[\text { Which nurse }]_{i} \text { and [which hostess }\right]_{j}\right]$ did Fred date $t_{i}$ and $t_{j}$ marry Bob, respectively?

Zhang does not discuss cases involving cross-clausal extraction. With regular ATB, the parallelism requirement in question is relaxed; i.e., it does not hold with cross-clausal ATB, as (20) shows.

(20) I wonder who $\mathrm{o}_{\mathrm{i}}$ [John saw $t_{\mathrm{i}}$ ] and [Peter thinks $t_{\mathrm{i}}$ kissed Mary].

The same holds for distributed extraction coordinations. ${ }^{6}$

(21) Which writer $r_{i}$ and which actor ${ }_{j}$ does John adore $t_{i}$ and Peter claim $t_{j}$ will succeed in Hollywood respectively?

The ATB requirement thus holds in the same way in distributed coordination constructions as with regular ATB constructions, which further indicates that the former are a type of ATB constructions although they do not involve extraction of the same element (hence the term non-ATB ATB).

In the following sections I will present additional cases of non-ATB ATB which are quite different from English examples like (6). We will see that the ATB requirement holds in these cases as well: although different elements are moving out of the conjuncts there must be movement out of each conjunct. The cases discussed in the following sections will also enable us to establish additional restrictions on non-ATB ATB.

\section{AP ATB in SC}

I now turn to a case of distributed ATB in Serbo-Croatian (SC) which has interesting additional properties. SC productively allows left-branch extraction of adjectives (see [11-16] among many others). ${ }^{7}$

(22) Crvena $_{i}$ se je meni [ $t_{i}$ suknja] dopala.

red self is me DAT $_{\text {skirts pleased }}$

'The red skirt pleased me.'

It also allows it in distributed coordinations. One difference from English wh-movement involving distributed coordination is that such cases involving adjectival ATB in SC do not require "respectively" (in fact, there is no clear counterpart of respectively in SC; note that in some cases respectively is not needed in English, see (93). ${ }^{8}$

(23) Crvene i bijele ona suknje i kapute prodaje.

red and white she skirts and coats is-selling

'She is selling red skirts and white coats.' 
(24) Crvena i bijela meni suknja i haljina smetaju.

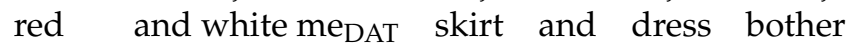
'The red skirt and the white dress bother me.'

It is also possible to have three adjectives in this type of constructions, as in (25), with the relevant traces indicated in (26).

(25) Crvena, bijeli i šareni meni suknja, kaput i šešir smetaju. red white and colorful me

(26) Crvena $_{i}$, bijeli $i_{j}$ šareni ${ }_{k}$ meni [ $t_{i}$ suknja], [ $t_{j}$ kaput] $i \quad$ [ $t_{k}$ šešir] smetaju. red white and colorful me $e_{\mathrm{DAT}}$ skirt coat and hat bother

Importantly, as in the case of English non-ATB ATB examples from Section 2, the ATB requirement is operative in the SC construction under consideration. Thus, (27), where ATB does not take place out of the last conjunct, is unacceptable. ${ }^{9}$

(27) ${ }^{*}$ Crvena $_{\mathrm{i}} \mathrm{i}$ bijeli red and white

$$
\text { meni [ } t_{i} \text { suknja], }
$$$$
\text { me } e_{\text {DAT }} \text { skirt }
$$

[t $t_{j}$ kaput] i coat and [šareni šešir] smetaju. colorful hat bother

One might try to argue that the ATB requirement in English cases such as (12) and (13) is somehow forced by respectively. This, however, would not extend to SC (26), where respectively is not present.

It should be pointed out that ATB-violating examples such as (27) improve if the first two conjuncts are pronounced as a single prosodic unit (followed by a pause), with another coordinator, as in (28). What is going on here is that suknja i kaput form a coordination, which is then coordinated with šareni šešir. In other words, we are not dealing here with a single coordination with three conjuncts, as in (26), (27), but with two separate coordinations, each of which has two conjuncts: suknja $i$ kaput forms a ConjP that is itself located in the Spec of a ConjP (the head of the second coordination takes šareni šešir as its complement), as shown in (29).

(28) ?Crvena $a_{i}$ bijeli $i_{j}$ mene ( $t_{i}$ suknja $i \quad t_{j}$ kaput) $i \quad$ [šareni šešir] iritiraju. red and white me DAT skirt and coat and colorful hat irritate 'The red skirt, white coat and colorful hat irritate me.'

(29) ?Crvena $i_{i}$ bijeli $j_{j}$ mene [ConjP1 ([ConjP2 $t_{i}$ suknja i $t_{j}$ kaput]) i [šareni šešir]] red and white me skirt and coat and colorful hat iritiraju.

irritate

This kind of examples also have consequences for the domain of application of the ATB requirement. While there is extraction out of each conjunct of ConjP2, this is not the case with ConjP1 in (29). What matters here is that the first conjunct of ConjP1, which is the only conjunct from which extraction takes place, is itself a ConjP. The ATB requirement apparently does not hold across ConjPs (in a configuration where a ConjP dominates a ConjP). ${ }^{10}$

This in fact holds for regular ATB as well, as indicated by (30) (assuming the same prosody as in (29), with the first two conjuncts pronounced as a single prosodic unit (with a pause following them); crvene here undergoes regular ATB extraction from the first ConjP-as result, "red" modifies both "skirts" and "dresses"; there is a potential interfering factor here that is controlled for in Fn. (47).

(30) ?Crvene $_{i}$ mene [ConjP1 ([ConjP2 $t_{i}$ suknje i $t_{i}$ haljine]) i [šareni šeširi]] red me skirts and dresses and colorful hats iritiraju. irritate

'Red skirts, red dresses and colorful hats irritate me.'

It should also be noted that there is evidence that we are dealing with actual extraction in the relevant cases. This is confirmed by their island-sensitivity. Thus, the presence of an 
adjunct island between the extracted APs and the remnant NPs causes ungrammaticality in (31). ${ }^{11}$

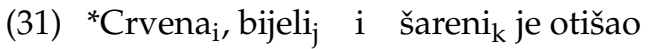
red white and colorful is left

zato što mene [ $t_{i}$ suknja], [ $t_{j}$ kaput]

i $\quad\left[t_{k} \quad\right.$ šešir $]$ iritiraju.

because me $e_{\text {DAT }}$ skirt coat

and hat irritate

'He left because the red skirt, white coat, and colorful hat irritate me.'

There is another rather interesting aspect of the SC construction under consideration. Consider (32). There are only two fronted APs in (32), with three nouns in the lower coordination. Yet, in contrast to (27), (32) is acceptable.

(32) Crvena i bijeli meni suknja, kaputi šešir smetaju. red and white me DAT skirt coat and hat bother

What is important here is that (32) is acceptable only on a particular meaning: 'red skirt, white coat, and white hat', where a traditional ATB dependency is formed between 'white coat' and 'white hat' with respect to 'white'. What makes this possible is that both 'coat' and 'hat' are masculine: the adjective that modifies them is also masculine (note that crvena and suknja are feminine).

(33) Crvena $_{i}$ i bijeli $j_{j}$ meni [ $t_{i}$ suknja], [ $t_{j}$ kaput] $i \quad\left[t_{j}\right.$ šešir] smetaju. red and white me $e_{\text {DAT }}$ skirt coat and hat bother

The ATB requirement is then still satisfied in (32): (32) is in fact acceptable only on the reading on which there is an AP-gap in the base position of each of the conjuncts in (32). What is particularly interesting about this example is that it involves a mix of non-ATB ATB and regular ATB. Examples such as (32) then provide evidence that non-ATB ATB can be mixed with true ATB.

Another example of this sort is given in (34), which involves regular ATB between 'red skirt' and 'red shirt' (košulja is feminine).

(34) Crvena $_{i} \mathrm{i}$ bijeli $\mathrm{j}_{\mathrm{j}}$ meni [ $\mathrm{t}_{\mathrm{i}}$ suknja], [ $\mathrm{t}_{\mathrm{i}}$ košulja] $\mathrm{i} \quad$ [ $\mathrm{t}_{\mathrm{j}}$ kaput] smetaju. red and white me $e_{\text {DAT }}$ skirt, shirt and coat bother

A question arises whether this kind of mixing of non-ATB ATB and regular ATB is also possible in English. It turns out that it is although constructions of this type are less acceptable in English than in SC possibly because of an additional processing load. (Gender agreement resolves the relevant filler gap dependencies in SC; this filler gap dependency resolution is not available in English. It is also possible that the presence of respectively interferes here, leading to an expectation that there should be three antecedents for the three gaps. ${ }^{12}$ )

(35) ?How many cakes and how many letters did Mary bake, John write, and Peter mail respectively?

(36) ?How many cakes and how many letters respectively did Mary bake, John write, and Peter mail?

(37) ?Which magazine and which book did Peter buy, John read, and Mary borrow respectively?

(38) ?Which magazine and which book respectively did Peter buy, John read, and Mary borrow?

Returning to SC, interestingly, in contrast to (33), (39) is unacceptable.

(39) ${ }^{*}$ Bijeli $_{i}$ i crvena $a_{j}$ meni [ $t_{i}$ kaput], [ $t_{j}$ suknja] i [ $t_{i}$ šešir] smetaju. white and red me coat skirt and hat bother

Apparently, a traditional ATB dependency can only be formed between contigious NPs here. There can be no ATB between 'red skirt' and 'red hat' given that the adjective needs to agree with the nouns and these nouns have different gender (suknja is feminine and šešir masculine). Also, there can be no ATB between 'white coat' and 'white skirt' since these 
nouns also have different gender (kaput is masculine and suknja feminine). Interestingly, there can apparently be no ATB between 'white coat' and 'white hat'. There is no gender disagreement issue here since the nouns have the same gender.

The same effect is found in English. Thus, (40), where given the pragmatics of the example regular ATB dependency has to hold between the first and the third conjunct, skipping the second conjunct, is worse than (36)-(38), where this is not the case. This contrast also provides evidence that the English and the SC construction in question should be treated in the same way (given that both exhibit the contiguity effect).

(40) ${ }^{*}$ How many letters $s_{i}$ and how many cakes ${ }_{j}$ did Peter write $t_{i}$, John bake $t_{j}$, and Mary address $t_{i}$ respectively?

We may be dealing here with a locality effect on traditional ATB formation, where it is not possible to skip a potential ATB site. ${ }^{13}$

Alternatively, this may be related to a general interpretive effect associated with distributed extraction coordinations. Notice first that examples like (6) are not ambiguous: the first trace must correspond to the first wh-phrase and the second trace to the second wh-phrase. In other words, only a crossing wh-trace dependency is possible here; a nesting dependency, which would give an interpretation where the first trace corresponds to the second wh-phrase, is disallowed. This is a general property of distributed extraction coordinations. Thus, (41) gives the only possibility for the distributed interpretation of the extracted adjectives in this SC example (ignoring the irrelevant regular ATB interpretation, on which each conjunct is red, white, and colorful), where all adjectives have the same gender, and (42) illustrates the same effect for English distributed coordination constructions involving three conjuncts, where the indices again indicate the only possibility for the interpretation of the conjuncts (the parallel behavior of the SC and the English construction under consideration in this respect can be taken as another argument for treating the two in a uniform manner).

(41) Crveni $_{i}$, bijeli $_{j} \quad i \quad$ šareni $i_{k}$ meni [ $t_{i}$ sako], [ $t_{j}$ kaput] $i \quad$ [ $t_{k}$ šešir $]$ smetaju. red white and colorful me $e_{\mathrm{DAT}}$ jacket coat and hat bother 'The red jacket, white coat, and colorful hat bother me.'

(42) Which book $_{\mathrm{i}}$, which magazine $\mathrm{j}_{\mathrm{j}}$, and which painting $\mathrm{k}_{\mathrm{k}}$ respectively did [John buy $\mathrm{t}_{\mathrm{i}}$, [Bill read $\mathrm{t}_{\mathrm{j}}$ ], and [Mary sell $\mathrm{t}_{\mathrm{k}}$ ]?

Distributed extraction coordinations apparently require crossing dependencies. Returning now to the unacceptable example in (39), which mixes non-ATB ATB and regular ATB, gender specification of the adjectives forces the dependencies shown in (43).

(43) *Bijeli $i_{i}$ i crvena $a_{j}$ meni [ $t_{i}$ kaput], [ $t_{j}$ suknja] $\mathrm{i} \quad$ [ $t_{i}$ šešir] smetaju. white and red me DAT coat skirt and hat bother

Example (43) involves a mixture of crossing and nesting dependencies (the last trace is involved in a nesting dependency). It then seems plausible that it is ruled out due to the general crossing dependencies requirement on distributed coordinations.

As for the source of the effect of question, notice that what we are dealing with here is essentially a matching effect: the order of the conjuncts within the newly formed ConjP must match the order of the conjuncts from which extraction takes place in the original ConjP. Given that in this kind of cases the co-ordination structure is in a sense "re-created" in a higher position, with another ConjP, it seems natural to assume that there should be some parallelism between the two coordinations where the order of the conjuncts in the higher ConjP should correspond to the order of the conjuncts (which contain the relevant gaps) in the lower ConjP, which means that the first conjunct should correspond to the first gap, the second conjunct to the second gap and so on. The result of this is strictly crossing dependencies. Under this approach the ordering effect is essentially a parallelism effect (see, however, the Appendix A, where the parallelism effect is deduced from independent considerations). 
Before concluding this section, one potentially interfering issue should be discussed. Consider (44). Refs $[37,38]$ show that SC examples such as (44) can involve either coordinated wh-phrases or coordinated clauses, with ellipsis taking place in the first conjunct (they implement ellipsis through multidominance structures).

(44) Ko i who and

'Who is

šta kupuje?
what is-buying
buying what?'

Evidence for the possibility of a clausal structure for (44) is provided by the possibility of examples such as (45), where a clitic (je) follows the first as well as the second whphrase: this indicates that the first conjunct is actually a clause, and the same holds for the second conjunct.

(45) Ko je i šta je kupio?

who is and what is bought

'Who bought what?'

A question then arises whether SC examples such as (24) could be analyzed as involving coordinated clauses with ellipsis in the first conjunct instead of involving coordination formation in the moved position. Crucially, (46) differs from (45) regarding clitic placement.

(46) ${ }^{*}$ Crvene su i bijele su meni suknje i haljine smetale.

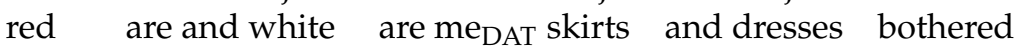

'The red skirts and the white dresses bothered me.'

The contrast between (45) and (46) then provides evidence that in (24)/(46) we are not dealing with a larger coordination: it really is APs that are coordinated here. In other words, we have here evidence that the construction in question does not involve a larger, clausal coordination with ellipsis in the first conjunct. ${ }^{14}$

Notice also that adjectives involved in the coordination in question must bear the same case, as shown by the unacceptability of (48) (as shown by (47), 'manage' assigns instrumental and 'sell' assigns accusative to its complement). The restriction would be very difficult to formulate if what we were dealing with here were a larger coordination (cf. $(47 \mathrm{c}))$, not coordination of adjectives.
a. On rukovodi malom fabrikom. he manages small INSTR factoryINSTR

b. On prodaje velike kuće. he sells big ACC houses $A C C$

c. On rukovodi malom fabrikom i prodaje velike kuće. he manages small INSTR factory INSTR $_{\text {and sells big }}$ ACC houses ACC $_{\text {INC }}$
(48) ${ }^{*}$ Malom $_{i} \quad$ i $\quad$ velike $_{j}$ on rukovodi $t_{i}$ fabrikom i prodaje $t_{j}$ kuće. small $_{\text {INSTR }}$ and big ACC he manages factory INSTR $_{\text {and sells houses ACC }}$

It is also worth noting here that SC clitics are second position clitics (see [39] and references therein); as such they are standardly used as a constituent-hood test (since they cannot follow more than one constituent). Clitic placement in (49) then confirms that crvene $i$ bijele is a single constituent, which is indeed the case under the coordination-in-the-moved position analysis. $^{15}$

(49) Crvene i bijele su meni suknje i haljine smetale.

red and white are me $\mathrm{DAT}_{\mathrm{T}}$ skirts and dresses bothered

'The red skirts and the white dresses bothered me.'

Additional evidence that we are dealing here with a regular coordination in the moved position is provided by comparing left-branch extraction non-ATB ATB cases, which involve multiple left-branch extraction with coordination, with multiple left-branch extraction cases that do not involve coordination. [44] discusses multiple left-branch extraction cases such as (50). ${ }^{16}$ 
(50) Onu $_{i} \quad$ staru $_{j}$ prodaje $t_{i} t_{j}$ kuću.

that old sells house

'He is selling that old house.'

(51) *Prodaje onu i staru kuću.

sells that and old house

'He is selling that old house.'

(52) *[Onu i staru $]_{i}$ prodaje $\left[t_{i}\right.$ kuću].

that and old sells house

Example (50) shows that multiple left-branch extraction of the demonstrative and the adjective is possible (left-branch extraction of both demonstratives and adjectives is in principle possible in SC). The elements in question cannot be coordinated within a single NP in situ, as shown by (51); not surprisingly, they also cannot undergo left-branch extraction as a coordination, as shown by (52).

Turning now to non-ATB ATB left-branch extraction, such cases also involve multiple LBE. Notice, however, that (24) contrasts with (53).

(53) ${ }^{*}$ Oni $_{i} \quad \mathrm{i}$ bijele $\mathrm{j}_{\mathrm{j}}$ meni [ $\mathrm{t}_{\mathrm{i}}$ kaputi] i [ $\mathrm{t}_{\mathrm{j}}$ haljine] smetaju.

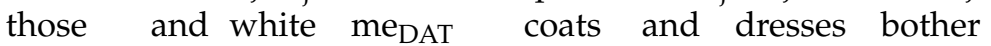

'Those coats and white dresses bother me.'

What we see at work in (53) is what is at work in (50), (51). The relevant elements, the demonstrative, and the adjective, can undergo left-branch extraction; in fact, they can be involved in multiple left-branch extraction, as shown by (50). However, these elements cannot be coordinated, as shown by (51), hence they cannot undergo left-branch extraction as a coordination (cf. (52)). The ungrammaticality of (53) is not surprising from this perspective: (53) is ruled out on a par with (51) because one and bijele cannot be coordinated. That the restriction in question is relevant in (53)) is not surprising given that elements that undergo non-ATB ATB are involved in a coordination with each other. However, in contrast to (51), where the demonstrative and the adjective are coordinated in their base position and modify the same noun, the demonstrative and the adjective obviously cannot be involved in a coordination in their base position in (53). This is so because of the interpretation of (53), which is "those coats and white dresses" — the demonstrative and the adjective do not modify the same noun in (53), in contrast to (51). The coordination in (53) can then only take place after movement since the relevant elements are clearly not coordinated in their base-position. The individual movements themselves also must be possible in (53), given that such multiple left-branch extraction is in principle possible, as shown by (50) (see [44]). Thus, (53) is ruled out because it involves illicit coordination, where the coordination takes place after movement. The data in question then also provide evidence that we are indeed dealing here with late coordination formation (i.e., non-base coordination).

Notice that we also have additional evidence here that non-ATB ATB examples involving left-branch extraction do not involve a larger coordination with ellipsis in the first conjunct. Under such an analysis we would not be able to appeal to the impossibility of coordination of a demonstrative and an adjective, i.e., the ungrammaticality of (51), since this is not what would be coordinated in (53) under that analysis. ${ }^{17}$

Another issue that is relevant here is that a clitic $(m u)$ can intervene between the demonstrative and the AP in (50), as shown by (54). Recall that this is not possible with non-ATB ATB constructions, as shown by (46).

(54) ?Onu $u_{i}$ staru $u_{i}$ prodaje $t_{i} t_{j}$ kuću.

that him $\mathrm{DAT}$ old sells house

'He is selling that old house to him.'

All this confirms the coordination in the moved position analysis of $(24) /(46)$. Elements undergoing multiple LBE need not move to the same position, hence a clitic can intervene between them, as in (54). Elements involved in non-ATB ATB (as in (46)), on the other hand, are located in the same position, in fact non-ATB ATB involves a coordinated phrase, 
hence a clitic cannot intervene between the relevant elements, which are coordinated with each other.

The above data, thus, provide additional evidence that coordination formation should not be restricted to base-generation (i.e., lexical insertion/external merge), i.e., it should not be restricted in such a way that it can only occur pre-movement.

In summary, in this section, we have seen another case of non-ATB ATB, which also involves non-base coordination formation and which is also subject to the ATB requirement. We have also seen that the ATB requirement does not apply across ConjPs. Furthermore, we have seen that non-ATB ATB can be combined with traditional ATB and that the crossing dependencies requirement on distributed coordination is maintained regardless of whether such constructions involve only non-ATB ATB or a mixture of non-ATB ATB and traditional ATB.

\section{Japanese Numeral Constructions}

Japanese floating quantifier constructions provide another case of non-ATB ATB extraction. ${ }^{18}$ Consider (55).

(55) John-ga [VP [pp yaoya-kara] [mikan-o 3-ko]-to [banana-o 5-hon] katta. John-NOM vegetable.store-from orange-ACC 3-CL and banana-ACC 5-CL bought 'John bought [3 oranges and 5 bananas] from a vegetable store.'

Importantly, it is possible to extract the NP from the conjuncts in (55), with a coordination structure recreated in a higher position (for some speakers 'respectively' is optional here, others require it; see also Fn. 18).

(56) John-ga [mikan-to banana]-o yaoya-kara (sorezore) [3-ko]-to

John-NOM orange and banana-ACC vegetable.store-from respectively 3-CL and

[5-hon] katta.

5-CL bought

Furthermore, the ATB requirement is also imposed in such cases, as shown by the contrast between (59), where extraction takes place from each conjunct, and (58), where this is not the case (extraction does not take place from the last conjunct). ${ }^{19}$

(57) John-ga yaoya-kara [mikan-o 3-ko]-to [banana-o 5-hon]-to John-NOM vegetablestore-from orange-ACC 3-CL and banana-ACC 5-CL and [budou-o 2-fusa] katta. grape-ACC 2-CL bought 'John bought 3 oranges, 5 bananas and 2 bunches of grapes from a vegetable store.'

(58) ?*John-ga [mikan-to banana]-o yaoya-kara (sorezore) [3-ko] to John-NOM orange and banana-ACC vegetable.store-from respectively $3-\mathrm{CL}$ and [5-hon] to [budou-o 2-fusa] katta.

5-CL and grape-ACC 2-CL bought

(59) John-ga [mikan-to banana-to budou]-o yaoya-kara (sorezore) John-NOM orange and banana and grape-ACC vegetable.store-from respectively [3-ko] to [5-hon] to [2-fusa] katta.

$3-\mathrm{CL}$ and $5-\mathrm{CL}$ and 2-CL bought

It should also be noted that this kind of non-ATB ATB is possible without the coordinator to in the higher position. In such cases another coordinator, sosite, appears in the higher position. ${ }^{20}$

(60) John-ga [mikan-o $\mathrm{o}_{\mathrm{i}}$ sosite

banana- $\left.\mathrm{o}_{\mathrm{j}}\right]$ yaoya-kara (sorezore)

John-NOM orange-ACC and banana-ACC vegetable.store-from respectively

[t $\mathrm{t}_{\mathrm{i}}$ 3-ko]-to [t $\mathrm{t}_{\mathrm{j}}$ 5-hon] katta.

3-CL and 5-CL bought 
The ATB requirement is imposed in this case too. Thus, (62), where extraction takes place from each conjunct, is better than (61), where extraction takes place from the first and the second, but not the third conjunct.

(61) ?*John-ga [mikan-o $\mathrm{O}_{\mathrm{i}}$ sosite banana-oj] yaoya-kara (sorezore)

John-NOM orange-ACC and banana-ACC vegetable.store-from respectively [ $\mathrm{t}_{\mathrm{i}}$ 3-ko] to [ $\mathrm{t}_{\mathrm{j}}$ 5-hon] to [budou-o 2-fusa] katta. 3-CL and 5-CL and grape-ACC 2-CL bought

(62) John-ga $\left[\right.$ mikan-o $_{i}$ sosite banana- $\mathrm{o}_{j}$ sosite budou- $\left.\mathrm{o}_{\mathrm{k}}\right]$ yaoya-kara John-NOM orange-ACC and banana-ACC and grape-ACC vegetable.store-from (sorezore) [ $\left.\mathrm{t}_{\mathrm{i}} 3-\mathrm{ko}\right]$ to $\left[\mathrm{t}_{\mathrm{j}}\right.$ 5-hon] to [ $\mathrm{t}_{\mathrm{k}}$ 2-fusa] katta. respectively 3-CL and 5-CL and 2-CL bought

As another parallel to SC, (61) and (58) are actually marginally acceptable if there is a pause following the second conjunct in the lower ConjP (i.e., if the first two conjuncts in the lower ConjP form a separate intonational phase). This is the same prosody as the one discussed above with respect to SC (28). Recall that this prosodic pattern, on which the first two conjuncts in (57) are pronounced as a single prosodic unit, has a different derivation, on which 'three oranges' and 'five bananas' form a coordination (as reflected in this unit also forming a prosodic unit), which is then coordinated with "two grapes". In other words, on this prosodic pattern we are dealing here with two separate coordinations, each of which has two conjuncts.

Notice also that both examples like (61) and examples like (58) show island sensitivity, as shown by (63) and (64) respectively, where an adjunct island intervenes between the final and the original position of the relevant elements. ${ }^{21}$

(63) ?*Mikan-o sosite banana-o Mary-wa [John-ga yaoya-kara

(sorezore)

orange-ACC and banana-ACC Mary-TOP John-NOM vegetable.store-from respectively

3-ko-to 2-hon katta-kara] okotta.

3-CL and 2-CL bought-because got.angry

'Mary got angry because John bought 3 oranges and 2 bananas from a vegetable store.'

(64) ?*Mikan-to banana-o Mary-wa [John-ga yaoya-kara (sorezore)

orange and banana-ACC Mary-TOP John-NOM vegetable.store-from respectively

3-ko-to 2-hon katta-kara] okotta

3-CL and 2-CL bought-because got.angry

'Mary got angry because John bought 3 oranges and 2 bananas from a vegetable store.'

The Japanese construction under consideration in this section thus represents another case of non-ATB ATB, where movement takes place out of each conjunct, but it is different elements that are moving out of the conjuncts. As in the case of non-ATB ATB examples from English and SC discussed above, the ATB requirement holds in this case too: although different elements are extracted, extraction must take place from each conjunct.

\section{When Is Non-ATB ATB Possible?}

The above data confirm the existence of non-ATB ATB, where there is movement out of each conjunct but different elements are moving out of the conjuncts. In other words, the ATB requirement should be stated in a such a way that it does not require that the same element moves out of each conjunct but simply that there is movement out of each conjunct.

There is another interesting property of non-ATB ATB. All the cases involving non-ATB ATB discussed above involve coordination formation in the moved position. What happens when non-ATB ATB is attempted without coordination formation in the moved position? Consider in this respect (65):

(65) *Which president do you wonder which famous writer John reads [articles about $t$ ] and [essays by $\mathrm{t}$ ] respectively?

Example (65) involves extraction of different elements from a single coordination without coordination formation in the higher position. In English, this requires moving 
wh-phrases to different +whCPs, which in turn brings in a wh-island violation. Still, (65) is clearly much more degraded than typical wh-island violations. ${ }^{22}$ The fact that the contrast between (65) and (6) is stronger than a typical wh-island violation suggests that coordination formation in the moved position is necessary for non-ATB ATB.

Consider also (66) and (67), which also involve non-ATB ATB without coordination formation in the moved position. Both examples are unacceptable. Furthermore, (67), where movement does not take place out of each conjunct (hence it is not in accordance with the ATB requirement), is even worse than (66), where movement does take place out of each conjunct (in ATB fashion) (in (67)) there are two moved elements and two gaps, while in (66) there are two moved elements and three gaps; the example mixes non-ATB ATB and ATB).

(66) *Which president do you wonder which famous writer John reads [articles about $t$ ], [essays by $\mathrm{t}$ ], and [tweets from $\mathrm{t}$ ] respectively?

(67) **Which president do you wonder which famous artist John reads [articles about $\mathrm{t}$, [essays by $\mathrm{t}$ ], and [tweets from Brady] respectively?

The contrast between (66) and (67) parallels in the relevant respect the contrast between SC (26) and (27), indicating that the ATB requirement still holds in such cases. Both examples are, however, unacceptable. What seems to be going on here is that performing non-ATB ATB without coordination formation in the moved position leads to a violation, call it a violation of requirement $X$ (to be discussed more below): $X$ is violated in both (65) and (66). The reason why (67) is even worse is that it violates $X$ as well as the ATB requirement that there needs to be movement out of each conjunct of a coordination.

Notice now that in (65), the wh-phrases that are moving out of the coordination are interpreted in different SpecCPs (i.e., different clauses). It is not out of question that this is the source of the ungrammaticality of (65); i.e., it may be that for some reason wh-phrases undergoing this kind of extraction must be interpreted in the same SpecCP, in which case (65) would not necessarily show that non-ATB ATB requires coordination formation in the moved position. This potentially interfering factor cannot be controlled for in English, but it can in SC, SC being a multiple wh-fronting language. Let us then test the possibility of non-coordinated non-ATB ATB with multiple wh-fronting in SC. The relevant examples are given below. (68), involving non-ATB ATB without higher coordination, is unacceptable. (69), its counterpart involving coordination in the higher position, is clearly better than (68). ${ }^{23}$

(68) *Prema kome ${ }_{i}$ za kim $_{j}$ su podržali [otpor $t_{i}$ ] i [potragu $t_{j}$ ]? to whom for whom are supported resistance and pursuit

(69) Prema kome $e_{i}$ i za kim $_{j}$ su podržali [otpor $t_{i}$ ] i [potragu $t_{j}$ ]? to whom and for whom are supported resistance and pursuit

'Resistance to whom and pursuit of who did they support?'

The interfering factor noted above with respect to English (65) also does not arise with respect to SC non-ATB ATB constructions discussed in Section 3. These constructions also require coordination formation in the moved position, as shown by the contrast in (70), where (70a) involves coordination formation in the moved position and (70b) does not, as well as the contrast in (71), involving wh-counterparts of constructions such as (70a), (70b), where the wh-phrases are interpreted in the same SpecCP. ${ }^{24}$

(70) a. Crvenu $u_{i}$ i bijelu je kupio [[ $t_{i}$ suknju $i \quad\left[t_{j}\right.$ haljinu $]$. red and white is bought skirt and dress

'He bought a red skirt and a white dress.'

b. *Crvenu bijelu je kupio suknju i haljinu.

(71) a. $\mathrm{Kakvu}_{\mathrm{i}}$ i čiju $\mathrm{j}_{\mathrm{j}}$ je ukrao [[ $\mathrm{t}_{\mathrm{i}}$ suknju] i [ $\mathrm{t}_{\mathrm{j}}$ haljinu]]? what-kind-of and whose is stolen skirt and dress

'He stole what kind of a dress and whose skirt.'

b. *Kakvu čiju je ukrao suknju i haljinu? 
The data discussed in this section thus indicate that non-ATB ATB requires coordination formation in the moved position, i.e., the elements undergoing non-ATB ATB must participate in a coordination in their final position.

Recall now the example noted in Fn. 5, repeated here, which is unacceptable although, just like (14), it involves extraction (of different elements) from each conjunct. The issue here is that, in contrast to (14), which involves wh-movement out of each conjunct, (72) involves wh-movement out of the second and third, and head-movement out of the first conjunct.

(72) * [Which newspaper ${ }_{i}$ and which magazine $\left.{ }_{j}\right]$ did $_{k}\left[\right.$ Mary $t_{k}$ write a book], [John may buy $t_{i}$, and [Bill will read $t_{j}$ ] respectively.

If the ATB requirement simply requires that there is movement out of each conjunct, there is then no violation of the ATB requirement here. The ungrammaticality of (72) can, however, now be accounted for independently of the ATB requirement. We have seen above that when different elements are extracted out of conjuncts of a single ConjP they must participate in a coordination in the higher position. This is not the case with did in (72). The unacceptability of (72) then follows independently of the ATB requirement.

But there is a more general issue here. In English, distributed coordination is also possible with A-movement, as in (73) (respectively is not needed in (73)).

(73) The dogs and the roosters barked and crowed all night [7], (p. 170).

Japanese, however, does not allow constructions such as (73) on the relevant reading (the distributed interpretation is difficult to obtain in (74), where the pragmatically implausible regular ATB reading where (the) dogs and (the) birds were both barking and flying is strongly preferred), whereas SC patterns with English in allowing them (see (75)), which can be taken to indicate that distributed coordination can be more restricted with A- than with $\mathrm{A}^{\prime}$-movement, given that such constructions clearly involve the former. ${ }^{25}$

(74) Inu-to tori-ga hitobanzyuu hoe-te ton-da.

dog-and bird-Nom all.night bark-and fly-Past

'(The) $\operatorname{dog}(\mathrm{s})$ and (the) bird(s) barked and flied all night.' (Japanese)

(75) Psi i pjevci su cijelu noć lajali i kukurikali.

dogs and roosters are all night barked and crowed (SC)

Importantly, I am unaware of any language that allows it with head-movement, i.e., I am not aware of any language that allows examples like (76).

(76) ${ }^{*}$ Will $_{i}$, can $_{j}$, and must $_{k}$ [John $t_{i}$ buy a book], [Peter $t_{j}$ sell a magazine], and [Mary $t_{k}$ borrow a novel] respectively?

There may then be something more general about head-movement that disallows distributed coordinations involving head-movement. Interestingly, [61] argues that head coordination is quite generally disallowed (see this work for evidence to this effect and discussion how traditional head coordination constructions should be treated ${ }^{26}$ ). If distributed extractions require that extracted elements be coordinated, as argued above, and if head coordination is quite generally disallowed, as [61] argues, it then follows that distributed coordinations with head-movement, as in (76), will be disallowed. The impossibility of distributed extraction involving head-movement can in fact be taken as another argument for the proposed coordination-in-the-moved position restriction on non-ATB ATB.

\section{Islandhood}

In this section I briefly note a locality effect associated with late coordination formation. SC allows extraction of conjuncts, as in (77) (see [3,4,62,63]).

(77) ?Knjige $_{\mathrm{i}}$ je Marko [ $\mathrm{t}_{\mathrm{i}} \mathrm{i}$ filmove] kupio.

books is Marko and movies bought

'Marko bought books and movies.'

Such extraction is, however, disallowed with constructions under consideration: after formation of non-ATB ATB coordination, conjunct extraction is not possible: 
(78) ${ }^{*}$ Crvene $e_{i}$ tvrdiš da se $\left[t_{i} i\right.$ bijeli $\left.i_{j}\right]$ meni dopadaju [ $t_{i}$ suknje] $i$ [ $t_{j}$ kaputi].

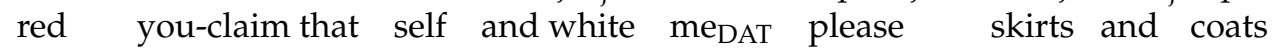
'You claim that red skirts and white coats please me.'

While it is not trivial to implement this formally, intuitively it seems clear what is going on here: ConjP that is formed after movement, i.e., ConjP not located in the base position, is an island (such ConjP would in fact be a barrier in [64]'s Barriers system).

In fact, not only conjunct extraction, but extraction out of a conjunct is also disallowed from a coordination formed by movement. This is shown by (79), involving ATB whmovement out of a late-formed ConjP located in SpecCP, which is clearly worse than simple extraction out of interrogative SpecCP, as in (80).

(79) *Which famous president $t_{i}$ do you wonder [which paintings of $\left.t_{i}\right]_{j}$ and [which books about $t_{i} l_{k}$ did he meet [fans of $t_{j}$ ] and [readers of $t_{k}$ ]

(80) ?Which famous president $t_{i}$ do you wonder [which paintings of $\left.t_{i}\right]_{j}$ John sold $t_{j}$ ?

Late-formed coordinations are apparently islands, disallowing any kind of extraction, even extractions that are in principle possible out of regular (i.e., base-generated) coordinations.

\section{When and How Is Late Coordination Formed?}

While the primary goal of this paper is not to provide a full analysis of distributed extraction coordinations-it is simply premature to do that before the empirical domain of the phenomenon is properly determined (the main goal of this paper being to make a contribution to that end) - in this section, I will nevertheless address the issue of how late coordination formation is to be implemented, focusing on its timing.

Zhang [7] discusses examples such as (6) and argues that they involve coordination formation through movement. More precisely, she argues that the higher ConjP is formed through sideward movement (see [8]). ${ }^{27}$ On this analysis, the higher ConjP of (6) (the relevant steps of the derivation of (6) are outlined in (81) is formed not by regular (i.e., upward) movement but by sideward merger of the relevant elements into ConjP (see (81c)), which is introduced into the structure directly in its final position, the interrogative SpecCP (see (81d)).

(81) a. [bought which book]

b. [read which magazine]

c. [Conjp [which book] and [which magazine]]

d. [CP [ConjP [which book] and [which magazine]] did John buy [which book] and Peter read [which magazine]]

While the analysis captures the most prominent property of distributive extraction coordination, namely that it involves late-coordination formation, it faces issues with some of the data discussed above. Recall that distributed extraction coordinations exhibit island effects, as illustrated again below with an inner island effect (cf. also SC (31) and Japanese (63), (64)). Under this analysis we cannot capture such islandhood effects, since the wh-phrases do not undergo movement out of the island.

(82) *[[How loudly] and [how softly]] didn't you say [[that John had spoken $t]$ and [that Peter had replied t]]? [33]

Another problem for Zhang's analysis is raised by the possibility of intermediate reconstruction effects, as in (83), where Condition A cannot be satisfied in either the final or the original (i.e., $\theta$ ) position of which picture of himself. (Under Zhang's analysis, only at these points are both John and which picture of himself present in the structure.)

(83) Which book and which picture of himself $f_{i}$ did John $n_{i}$ say that Mary bought and Sue sold respectively?

Parasitic gap constructions such as (8), repeated here, also raise an issue for Zhang's analysis.

(84) [CP $_{\text {[Conjp }}[\text { Which secretary }]_{1}$ and [which programmer] $]_{2}$ did Jerome respectively fire $t_{1}$ after finding $t_{1}$ drunk and hire $t_{2}$ after finding $t_{2}$ sober]? [2], (p. 136) 
The wh-phrases that participate in late coordination license parasitic gaps within their initial conjuncts here. As is well-known, a wh-phrase in situ cannot license a parasitic gap: a parasitic gap is licensed by a moved wh-phrase that c-commands the parasitic gap. Under Zhang's analysis, there is never a c-command relationship between the moved wh-phrases and the parasitic gaps which they license in (84).

These facts indicate that some regular (i.e., upward) movement must be involved in the derivation of distributed extraction coordinations. Under Zhang's analysis there is no regular movement, as a result of which the coordination is formed (i.e., integrated into the structure) in the final position. While this captures the late-coordination formation requirement, it essentially does it too late. However, while the above facts indicate that regular movement must also be involved in the derivation of distributed coordinations (note that sideward movement obviates island effects, see [8] and the discussion below) they do not necessarily mean that Zhang's sideward-movement analysis is fatally flawed. The late-formed ConjP can still be formed through sideward movement, as long as this ConjP is introduced into the structure earlier, not in the final position (e.g., within the same phase as the original ConjP, but this will be revised below), in which case the late-formed ConjP would be moving out of the island in (82), and the movement would bring the anaphor close enough to John in (83) to satisfy Condition A during the derivation. (This would still leave (84) unaccounted for; I will return to that example below-see the discussion of (119), which resolves the issue in question.) The modification of Zhang's analysis, on which distributed coordinations involve a combination of sideward movement and regular movement, as a result of which the higher coordination is formed earlier than on Zhang's analysis (though it is still formed during the derivation) is in the spirit of the well-known fact that in ATB constructions, there cannot be an island boundary between the edge of the second conjunct and the original extraction site within that conjunct, which under Nunes's sideward-movement analysis means that the relevant element needs to get to the conjunct edge, i.e., 'close' to its sideward movement site in the first conjunct. It is then not that surprising that the newly formed ConjP, which is also formed through sideward merger from the original ConjP under Zhang's analysis, cannot be indefinitely far from the original ConjP, which means that it should be introduced into the structure earlier, not in the final position.

\subsection{Deducing the Coordination in the Moved Position Requirement}

Involving sideward movement in derivational coordination formation may help us deduce the coordination in the moved position requirement, established in Section 5, according to which extraction of different elements from a coordination is possible only if they are themselves later involved in a coordination. The derivationally-formed coordination is essentially semantically expletive, the elements involved in our derivationally-formed coordination are not interpreted as coordinated. For example, the interpretation of (6) is 'which book did John buy and which magazine did Bill read', there is no coordination of which book and which magazine in the interpretation of this example. Similarly, there is no coordination of the dogs and the roosters in the interpretation of (73), whose interpretation is that 'the dogs barked and the roosters crowed'. The same holds for any of the SC examples discussed above; thus, there is no coordination of 'to whom' and 'for whom' in the interpretation of (69). In fact, SC examples such as (23) and (24) are ambiguous: on one reading, the adjectives are interpreted as coordinated (on that reading, (23) is interpreted as 'she is selling red and white skirts, and she is selling red and white coats'). This is not the case on the other reading, which we have been focusing on above, on which (23) is interpreted as 'she is selling red skirts and white coats'. The ambiguity is easily captured if on the latter reading the higher coordination is indeed expletive since the adjectives are not interpreted as coordinated on that reading.

That the higher coordination is not itself interpreted (see below for additional evidence to this effect) suggests that it is present for a formal reason. Sideward merger in fact provides a straightforward formal reason for that. It seems safe to assume that it is 
not possible to move different elements out of a single ConjP. Sideward merger is the mechanism that makes it possible to get around that restriction. As noted above, sideward merger was originally employed by [8] to get around islandhood/locality effects: sideward merger out of a context that would induce a locality/islandhood effect voids that effect. Sideward merger is then also what makes it possible to get around the restriction on moving more than one element out of a single coordination. The relevant elements are sideward merged before they move out of the ConjP. The derivationally formed coordination is then introduced into the structure. But crucially, the relevant constructions then never involve regular movement of different elements out of a single coordination (despite appearances). Sideward merger is then needed to get around the restriction in question, and derivational coordination formation is exactly what provides the needed sideward merger mechanism.

Notice that a single element can move out of a Conj $\mathrm{P}$ - this is in fact what happens with regular ATB. This is not surprising. ConjP is traditionally considered to be an island, this is in fact what the ban on extraction out of coordinations implies. In the phasal system, it is then natural to assume that ConjP is a phase, given that phases have a potential for inducing locality violations $\left([5,63]\right.$ in fact propose that ConjP is a phase). ${ }^{28}$ There are a number of analyses of regular ATB where movement takes place only out of the first conjunct. This is, e.g., the case with the often assumed null Operator movement analysis (see e.g., [65,66]), on which a null Op moves within non-initial conjuncts but there is no movement out of these conjuncts: movement takes place only out of the initial conjunct. The same holds for [8]'s sideward movement analysis, where XP participating in an ATB construction is merged in its theta-position in the second conjunct, then re-merged in the theta-position in the first conjunct, undergoing movement only from that conjunct. ${ }^{29}$ Under both of these analysis of regular ATB, upward movement out of ConjP takes place only out of the initial conjunct. In (3), it takes place from SpecDP of the first conjunct, where who is located prior to the extraction out of ConjP. Under $[67,68]$ 's approach to the PIC, who at the edge of the first conjunct is actually located at the edge of ConjP. ${ }^{30}$ If two different elements were to undergo movement out of the same ConjP, the second one could not get to the edge of ConjP (the element at the edge of the second conjunct is not at the edge of the ConjP). Sideward merger into another ConjP is then what enables this element to get out of the problematic ConjP without undergoing actual movement out of it. ${ }^{31}$

To summarize, under the suggestion made here the derivational ConjP formation provides a formal mechanism that makes it possible for more than one element to get dislocated from a single ConjP. This also deduces the restriction established above that different elements that move out of a single ConjP must themselves get coordinated. It also captures the semantic explitiveness of late coordination formation, given that it is present for a strictly formal reason.

The semantic explitiveness of late coordination formation enable us to capture another property of late coordination formation constructions. And is not the only coordinator in English. What is interesting is that even when a different coordinator is used in the lower, semantically contentful coordination, and is used in the higher, semantically expletive coordination. Thus, while the literature discusses only cases with the coordinator and, it is possible to use the disjunctive or in the lower position of the constructions under consideration; still, only and is possible in the higher, non-interpreted coordination, or is not possible, as shown by (85) (we are looking at the distributed reading here, e.g., "either John bought Moby Dick or Mary sold Vogue").

(85) a. Which book and which magazine did John buy or Mary sell respectively?

b. *Which book or which magazine did John buy or Mary sell respectively?

What is essentially going on here is that the most neutral coordinator is used in the derivationally-formed coordination, even if a different element is used in the lower position (note that this shows that we are not simply dealing here with coordinator copying), which is not surprising if the higher coordination is not interpreted (i.e., if it is indeed semantically expletive). 
Also relevant here are the SC examples in (86), (87) (noted by Ksenia Zanon, p.c., for Russian). Repetition of the coordinator $i$ 'and' in SC brings in an additional meaning, as indicated by the rough translation of (86). Importantly, this kind of coordination cannot be used in derivationally-formed coordination, as shown by (87). ${ }^{32}$ Note also that (87) becomes better if the first $i$ 'and' is dropped.

(86) Ona prodaje i suknje i kapute.

she sells and skirts and coats

'She sells both skirts and coats.'

(87) *I crvena i bijela meni i suknja i kaput smetaju.

and red and white me $\mathrm{DAT}_{\mathrm{DA}}$ and skirt and dress bother

'The red skirt and the white coat bother me.' (SC)

All this makes sense if the derivationally-formed coordination is indeed semantically expletive (see below for additional evidence to this effect) - this is why the neutral coordinator is used to perform that function. This in turn confirms that the late-formed coordination is present for a strictly formal reason; as discussed above, this is what enables extraction of different elements from a single coordination, deducing the generalization from Section 5 that such extraction is possible only in the presence of a higher coordination.

\subsection{Where Is Late-Formed ConjP Inserted?}

Returning now to the derivation of non-ATB ATB constructions, let us now address more closely the question of how close to the original ConjP, the late-formed (i.e., derivationally-formed) ConjP is introduced. To address the question I will look at distributed coordination under A-movement. First, examples such as (88) indicate that what is present in the $\theta$-position of the relevant conjuncts (given the predicate-internal subject hypothesis) is not the you and me ConjP: only you is present in the $\theta$-position of the first conjunct and only me is present in the $\theta$-position of the second conjunct, given that each conjunct agrees separately in (88), in contrast to (89). These examples thus confirm that elements involved in distributed extraction coordinations start the derivation separately, as expected given the interpretation of such constructions. (For additional arguments to this effect based on binding, see (100), (101), and (103) below; the data in question quite conclusively show that the conjuncts start the derivation separately.)

(88) He wants you and me to respectively go out of your mind and (go) out of my mind.

(89) cf. You and I are going out of our $/{ }^{*}$ my $/{ }^{*}$ your mind(s) [2], (p. 161).

In (88) the conjuncts trigger agreement separately. In (90), on the other hand, they trigger it (in fact must trigger it, cf. (91), jointly.

(90) A dog and a rooster were barking and crowing all night.

(91) *A dog and a rooster was barking and crowing all night.

This means that late coordination must be formed before subject-verb agreement is determined here. In light of this I will use such constructions as a diagnostic for determining when exactly the derivationally-formed coordination is inserted into the structure. I will consider the constructions discussed in this section under $[67,68]$ approach to agreement, where agreement is established through the Agree relation holding between a probe and a goal, leaving it to the reader to verify that the conclusions reached below can also be maintained under e.g., [71]'s approach, where agreement is established in a Spec-Head relation (though with somewhat different derivations). Under the Agree analysis, when the relevant agreement relation is established ConjP must be located lower than $\mathrm{T}$, so that $\mathrm{T}$ can probe it (which means $\mathrm{T}$ must c-command it).

Consider (90) in light of this. The relevant part of (90) can be derived as in (92) (only the relevant elements are shown in the structures below): we have a vP\&vP coordination in the lower position, with the subjects still not being conjoined with each other at this point. Another ConjP (what I have referred to above as late/derivationally-formed ConjP) is then formed through sideward movement $(92 \mathrm{~b})$. Given that this ConjP must be higher 
than the $\theta$-positions of the relevant elements, as discussed above (cf. (88)), and that it must be below $\mathrm{T}$ so that $\mathrm{T}$ can probe it, there must then be a phrase between vP and TP, with the late-formed ConjP (see (92b)) introduced into the Spec of this phrase (see (92c); I leave open the identity of this phrase, referring to it as XP below). T then probes the late-formed ConjP (92d), before the latter moves to SpecTP (92e). ${ }^{33}$

(92) a. [Conjp [vP a dog ... ] and [vp a rooster ... ]]

b. [Conjp a dog and a rooster]

c. [XP [ConjP a dog and a rooster] X [ConjP [vP a dog ... ] and [vP a reoster ... ]]

d. T [XP [ConjP a dog and a rooster] X [ConjP [vP a dog ... ] and [ ${ }_{\mathrm{vP}}$ a rooster ... ]] I___ I Agree

e. [TP [ConjP a dog and a rooster]] T [XP [Conjp a dog and a roester] X [ConjP [vP a dog ... ] and [ $\mathrm{vP}$ a röster ... ]]

Additional structure then needs to be present between $\mathrm{T}$ and vP so that the higher ConjP can be inserted into the structure outside of the lower ConjP but still below T (92c). This is straightforward in examples such as (90), involving an auxiliary. It also needs to be the case in examples such as (93). ${ }^{34}$ I take this not to be an issue, given that many authors have anyway argued for additional structure between TP and vP even for examples such as (93) (see [69,72-77] among others).

(93) A dog and a rooster barked and crowed all night.

Consider now a very interesting example in (94). ${ }^{35}$

(94) John and Mary were hunting lions and were frightened by snakes respectively [78].

What is particularly interesting about this example is the discrepancy between agreement and interpretation within the conjuncts: what is interpreted in the relevant $\theta$-position of the first conjunct is John, and what is interpreted in the relevant $\theta$-position of the second conjunct is Mary. Yet, the agreement within the conjuncts is with John and Mary. ${ }^{36}$ Let us see how this mismatch can be captured.

First, the lower coordination here must be on a higher level than in (90) - it cannot be a vP\&vP coordination given that the auxiliary is present inside each conjunct. The auxiliary is plural (although what is interpreted as the subject of each conjunct is singular), which means that the auxiliary agrees with the late-formed ConjP. So, what has to happen here is that the auxiliary agrees with the late-formed ConjP, just as in (90), but the auxiliary must be within the lower ConjP, in contrast to (90).

Note first that, quite independently of the issues under consideration here, there are two ways of analyzing such constructions, as noted in [80]. If only phrases can be coordinated, the subject and the auxiliaries cannot be located in the same phrase here, given that the subject is outside of the coordination and the auxiliaries are inside of the coordination-such examples would then provide evidence for a return to split Infl. (94) would then involve TP\&TP coordination, with the subject undergoing ATB-movement out of each conjunct to the Spec of a higher projection, which for ease of exposition I refer to is as $\mathrm{YP}^{37}$ Alternatively, if traditional bar-level coordination is allowed, (94) can involve $\mathrm{T}^{\prime}$-coordination, with the subject undergoing ATB-movement from each conjunct to SpecTP. The choice between the two analyses is immaterial here, I will adopt the former for ease of exposition (the reader should bear in mind though that both analyses are compatible with the discussion below).

Consider then (94). The derivation will proceed similarly to (90), as shown in (95)-(98): John and Mary are inserted in their $\theta$-positions, i.e., the positions where they are interpreted, separately (95). Late coordination is then formed (96), and inserted into SpecXP of each conjunct (97). Since XP is located lower than the auxiliary, each auxiliary will probe this ConjP, resulting in plural agreement on the auxiliary. The late-formed ConjP then undergoes ATB movement out of the coordination (98); what is coordinated here is TP\&TP, hence lower ConjP (i.e., the ConjP that is not late-formed) dominates TP). 
(95) [vP John hunting lions] b. [vp frightened Mary by snakes]

(96) [Conjp John and Mary]

(97) [TP were-T [XP[Conjp John and Mary] X[vP John hunting lions] and [TP were-T [XP [ConjP John

$$
\text { I_l Agree }
$$

| Agree and Mary] X [vP frightened Mary by snakes]

(98) [YP [Conjp John and Mary] [Conjp [TP [XP [ Conjp John and Mary] [vP John hunting lions] and [TP were-T [xp [eonjp fohn and Mary] [vP frightened Mary by snakes]

The example, which shows a mismatch between agreement and interpretation in the second conjunct, can then be accounted for.

\subsection{Binding and Subject-Oriented Anaphors}

In the derivations of non-ATB ATB constructions discussed above the conjuncts start separately, the coordination being formed during the derivation and inserted into the structure above the position where the relevant elements were originally generated. Strong evidence that this is indeed what is going on in the constructions under consideration is provided by the behavior of the relevant elements regarding binding, in particular, by the fact that depending on their position the relevant elements can function as binders either jointly or separately. (99) illustrates the former case: the derivationally-formed coordination, John and Mary, binds the reciprocal.

(99) [John and Mary $]_{i}$ seem to each other ${ }_{i}$ to be the best candidate in the election and the best nominee for the convention respectively.

In (100), on the other hand, the conjuncts function as binders separately: John binds himself and Mary binds herself.

(100) $\left[\mathrm{John}_{\mathrm{j}}\right.$ and Mary $\mathrm{k}_{\mathrm{i}} \mathrm{i}_{\mathrm{i}}$ hired himself $\mathrm{f}_{\mathrm{j}}$ and nominated herself $\mathrm{k}_{\mathrm{k}}$ respectively.

The dual behavior with respect to binding is easily captured under the current analysis: when the anaphor is located low in the structure, namely below the position in which the relevant elements are base-generated (i.e., inserted prior to derivational coordination formation), the relevant elements function as binders separately (this is the case with (100)). On the other hand, when the anaphor is inserted high in the structure, where only the derivationally-formed coordination is higher than the anaphor, the relevant elements function as the binder together (this is the case with (99)).

Furthermore, (101) (due to Steven Franks, p.c.) confirms that the conjuncts must start separately. In (101), they induce a blocking effect for binding separately, as the simplified structure in (102) shows (the closest subjects for the anaphor are $t_{i}$ in the first conjunct and $t_{j}$ in the second conjunct). ${ }^{38}$

(101) *John and Mary seem to be the best candidate in each other's campaigns and the best nominee in each other's parties respectively.

(102) ${ }^{*}\left[\mathrm{John}_{\mathrm{i}} \text { and Mary }\right]_{\mathrm{k}}$ seem to be $\mathrm{t}_{\mathrm{i}}$ the best candidate in each other' $\mathrm{s}_{\mathrm{k}}$ campaigns and $\mathrm{t}_{\mathrm{j}}$ the best nominee in each other' $s_{\mathrm{k}}$ parties respectively.

Furthermore, the individual conjuncts can function as binders of subject-oriented anaphors, as shown by (103) (svom is a subject-oriented anaphor).

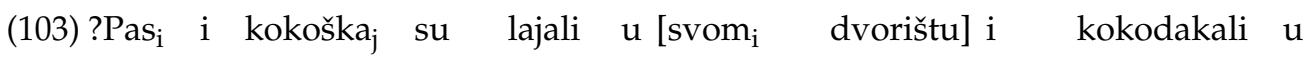
dog and chicken are barked in its.anaphor yard and crowed in svom $_{\mathrm{j}}$ kokošinjcu]. its.anaphor hen-house

'A dog and a chicken barked in its yard and crowed in its hen house.'(SC)

Such examples have important consequences for the debated and unsettled issue of how subject-oriented anaphors should be analyzed. What is important here is that what is located in SpecvP are the individual conjuncts but what is located in SpecTP and what agrees with $\mathrm{T}$ is the whole coordination, as the simplified derivation in (104) shows. 
(104) [Tт $\left[\text { Pas }_{i} \text { i } \quad \text { kokoška }_{j}\right]_{k}$ su [XP $t_{k}\left[\right.$ ConjP $\left[{ }_{v P} t_{i}\right.$ lajali $u \quad$ svom $_{i}$ dvorištu $]$ i dog and chicken are barked in its yard and

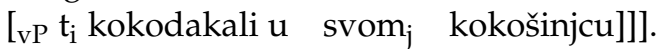
crowed in its hen-house

This is a rather rare mismatch, which can help tease apart different approaches to subject-oriented anaphors. What functions as the binder of the subject-oriented anaphors in (103)/(104) is the element in SpecvP, not the element in SpecTP or the element that undergoes Agree with T. (103) then provides evidence for approaches where the binder of subject-oriented anaphors is (or can be) the element located in SpecvP and against approaches where the element located in SpecTP and/or the element that undergoes Agree with $\mathrm{T}$ functions as the binder. There are many different approaches along the latter lines (see e.g., [85-87]), examples such as (103) provide evidence against all of them (I discuss the implications of distributed extraction for subject-oriented anaphors in more detail in work in progress).

\subsection{Where Is Agreement?}

The agreement/semantics mismatch constructions also have ramifications for an important question, where is agreement (i.e., what is its locus). It is standardly assumed that although agreement surfaces on the verb, it is not actually on the verb, i.e., its source is somewhere else (but see [88] for a proposal that in V-raising languages, the agreement is actually on the verb). It is certainly not a priori clear what the source of agreement is, whether the verb has it to start with (the verb is in fact where the agreement surfaces), or it is somewhere higher up (like on T/I). Semantics/agreement mismatches discussed above provide evidence for the latter (including for V-raising languages). If the source of agreement is the verb itself, not a higher head like T/I, given the standard assumptions regarding the locality of agreement and the VP-internal subject hypothesis, we would expect the verb to show singular agreement in (105) (cf. (105b)). What is going on here is that the subject of the verbal projection and the subject of the clause are different elements-the coordination is the subject of the latter but not the former. That the agreement here is with the coordination can then be taken to provide evidence that the source/locus of agreement is not its host, the verb. The same point can be made with SC, where the verb raises out of vP (see [39,89]); in fact both the auxiliary and the participle show plural agreement in (106a), indicating that even when it comes to the agreement that shows up on the participle, the verb is not the source/locus of the agreement.

(105) a. In this neighborhood, a dog and a rooster bark and crow all night.

b. [vP a dog barks] ...... . [ ${ }_{\mathrm{vP}}$ a rooster crows] (expected if the verb agrees)

(106) a. Pas i pjevac su cijelu noć lajali i kukurikali. dog and rooster are all night barked.pl and crowed.pl

b. Pas i pjevac non-stop laju i kukuriču. dog and rooster non-stop bark.pl and crow.pl (SC)

The system developed above may also enable us to account for some rather puzzling constructions noted by [83]. Consider (107) and (108), focusing on the former example (108) is a result of a familiar ordering effect with late coordination constructions discussed briefly above, and in more detail in the Appendix A).

(107) John and Mary saw himself and herself (respectively).

(108) *John and Mary saw herself and himself (respectively).

In the current system, (107) can be analyzed as involving late coordination formation for both the subject and the object, as shown below.

(109) a. [vp John saw himself] b. [vp Mary saw herself]

(110) a. [ConjP1 John and Mary] b. [ConjP2 himself and herself]

ConjP1 is then inserted into SpecXP from (92) and ConjP2 undergoes right node raising (more on right node raising below). Agreement in this kind of double late coordination 
constructions works as in the constructions discussed above, as illustrated by (111), and can be accounted for in the same way.

(111) John and Mary like/*likes himself and herself (respectively).

There is, however, one wrinkle raised by such constructions, which is that only one verb is pronounced. I suggest that there actually is coordination of the vPs here. The derivation discussed above (cf. (109), (110)) would lead to John and Mary saw and saw himself and herself. It is possible that a haplology motivated PF deletion takes place here, deleting and saw. There is a potential alternative. A number of authors have argued that verbs in English undergo short V-movement (see e.g., [90-92]; such analyses often assume overt object shift in English, which would not affect anything given the discussion below). Under this analysis, and still assuming that there is vP coordination here, the verb would undergo across-the-board head movement out of the vPs in (109). The only thing that would remain in the coordinated vPs would then be the coordinator itself. I suggest that in such a case, where independent movement operations move everything out of a coordinated phrase but the coordinator, the coordinator itself is deleted.

\subsection{Right Node Raising and Tough-Constructions}

In the examples discussed above, the late-formed coordination undergoes whmovement (cf. (6)) or A-movement to SpecIP (cf. (90)), whose derivation is given in (92). There are other movement operations that the late-formed coordination can undergo, like right node raising (112) or tough-movement (113); additionally, SC and Japanese examples discussed above involve scrambling).

(112) John sold, and Mary bought, gold rings and raw diamonds from South Africa respectively [93].

(113) George and Martha are respectively easy for me to fool and hard for anyone to take advantage of [79], (p. 294).

While exploring the issue in detail would take us beyond the scope of this paper, I will briefly note here that distributed coordination constructions may have some implications for the proper analyses of right node raising and tough-constructions. Thus, (113) seems to be difficult to handle under the null Op-movement analysis of tough-constructions, where what undergoes movement is a null Op that is licensed by a co-indexed c-commanding element, as in $\mathrm{John}_{i}$ is Op $\mathrm{p}_{i}$ tough to please $t_{i}$. In (113), it is not clear that there would ever be a c-command relationship between George and Martha and the null operators that each of these DPs would need to license (for discussion and comparison of different analyses of tough-constructions, see [94]).

Regarding right node raising, constructions such as (112) raise a serious problem for most accounts of right node raising (e.g., the ATB rightward movement or the PF deletion one; see [93]), since gold rings and raw diamonds from South Africa would be generated in the object position of each verb, which would give us wrong interpretation (the whole thing should then be interpreted as the object of each verb). The late coordination formation analysis straightforwardly resolves the issue since under this analysis the coordination is not present in the base: what is present in the base (i.e., the relevant theta-positions) is simply gold rings in the first conjunct and raw diamonds from South Africa in the second conjunct. The coordination in question is formed derivationally (the relevant elements are not interpreted as coordinated, as discussed above). Under the rightward movement analysis, the derivationally-formed coordination can then be inserted in the right-node raised position. ${ }^{39}$

\section{Movability}

Returning to the derivation of non-ATB ATB constructions, we have seen above that the coordination that participates in agreement is formed during the derivation. Looking at the structures in (92) and (98), we can see that the late-formed ConjP is inserted into the Spec of the first projection (not counting the lower ConjP in determining the first projection) 
above the position where the relevant elements are interpreted. ${ }^{40}$ Such examples may then help us determine the timing of derivationally-formed coordination insertion into the structure (assuming that they are illustrations of a broader pattern): based on such examples I then tentatively conclude that the derivationally-formed ConjP is inserted into the first projection above the position where the relevant elements are interpreted-(this can even be within the original ConjP, in which case the derivationally formed ConjP is inserted in both conjuncts, undergoing regular ATB out of the lower ConjP). The precise locality condition - "the first projection" - in the above statement may end up being revised upon future scrutiny of distributed coordinations ${ }^{41}$-what is important here is that the derivationally-formed ConjP is inserted very close to the positions where the relevant elements (i.e., its conjuncts) are interpreted (for the reason why this is the case, which ties the issue to the ordering of elements participating in late-coordination formation, see Appendix A).

The SC construction discussed in Section 3 can help us become more precise regarding the derivation of non-ATB ATB constructions, the reason for that being that with left-branch extraction (LBE), which is employed in the SC construction in question, it is possible to introduce a locality/islandhood effect very close to the base-generation position of the relevant elements. However, before we discuss that, one point needs to be emphasized.

In any language I am aware of, only mobile elements can participate in ATB non-ATB constructions. The SC construction discussed in Section 3 involves LBE, which is not possible in English, but is possible in SC. While non-ATB ATB involving LBE is possible in SC, as we have seen above, it is not possible in English (114a), a language which disallows $\operatorname{LBE}(114 b){ }^{42}$

(114) a. *Red, Mary bought dresses

b. *Red and blue, Mary bought houses and dresses.

The effect in question is actually also illustrated with English (11), repeated here.

(115) a. [Which nurse $]_{1}$ and [which hostess $]_{2}$ did Ernest sell cocaine to $t_{1}$, and George sell heroin to $t_{2}$, respectively?

b. ${ }^{*}[\text { Which nurse }]_{1}$ and [which hostess $]_{2}$ did Ernest sell $t_{1}$ cocaine and George sell $t_{2}$ heroin, respectively? [2], (p. 135)

c. cf. Which nurse ${ }_{1}$ did Ernest sell cocaine to $t_{1}$

d. ${ }^{*}$ Which nurse ${ }_{1}$ did Ernest sell $t_{1}$ cocaine?

As noted above, in contrast to the prepositional double object constructions (115c), the indirect object in DP DP double object constructions cannot undergo wh-movement (115d) ${ }^{43}$ It also cannot participate in distributive extraction coordinations, as shown by (115b), which contrasts with (115a).

As another illustration of this effect, there are prepositions in English which disallow stranding:

(116) a. Jerome tickled Marsha in that way.

b. *What way did Jerome tickle Marsha in?

c. cf. In what way did Jerome tickle Marsha?

d. Ernie did it for someone else's sake.

e. *Whose sake did Ernie do that for?

f. For whose sake did Ernie do that? [2], (p. 127)

Informally, we can consider the PPs in (116) to be barriers, which renders the Pcomplements in (116) immobile (note that the whole PP can move). Importantly, the same effect is found with the distributive extraction coordination in (117), which involve the PPs in question.

(117) * What way ${ }_{i}$ and whose sake $e_{j}$ did Jerome tickle Marsha in $t_{i}$ and Peter hugged Mary for $t_{j}$ respectively?

(118) cf. In what way $y_{i}$ and for whose sake ${ }_{j}$ did Jerome tickle Marsha $t_{i}$ and Peter hugged Mary $t_{j}$ respectively? 
The mobility requirement (which is essentially a locality-of-movement requirement) is surprising from the point of view of Zhang's sideward merger analysis. Sideward movement/merger was originally employed by Nunes to get around islandhood/locality effects (provided it takes place while the island is an independent root phrase, which is the derivation we are focusing on): sideward movement/merger out of a context that would induce a locality/islandhood effect voids that effect. Whatever locality/islandhood effect is involved in (114), (115b), and (116) (see, respectively, [11,13], [97,98], and [2,98], among others), sideward merger should be voiding it. What these facts then indicate is that the relevant elements undergo regular movement before sideward merger into another ConjP (i.e., there is a no-directly-from-the-interpreted-position restriction on derivational ConjP formation).

The parasitic gap constructions discussed above also require this movement. Consider again (119).

(119) [Which secretary $]_{1}$ and [which programmer $]_{2}$ did Jerome respectively fire $t_{1}$ after finding $t_{1}$ drunk and hire $t_{2}$ after finding $t_{2}$ sober? [2], (p. 136)

As noted above, a parasitic gap is licensed by a moved wh-phrase that c-commands the parasitic gap. In accounts like [8,34], it is not necessary for the wh-phrase to move to SpecCP to license a parasitic gap; movement to a lower position can do it. In fact, under Nissenbaum's account the wh-adjuncts in (119) are adjoined to their vPs, and the wh-phrases crucially need to move to adjoin to these vPs to license the parasitic gaps. This is the crucial step in parasitic gap licensing in this account. What is important for our purposes is that the wh-phrases need to undergo regular movement to license parasitic gaps within their conjuncts before undergoing sideward merger into ConjP in (119)_immediate sideward movement, as in Zhang's analysis, would not be sufficient for parasitic gap licensing. I then take the above facts to indicate that the relevant elements undergo regular movement before sideward merger into another ConjP. ${ }^{44}$

The SC construction from Section 3 can help us pinpoint the timing of regular and sideward movement. What is relevant here is that, in contrast to regular LBE as in examples such as (22), what is in the literature referred to as deep LBE, illustrated by (121), is disallowed (see [11-13,99] among others). With deep LBE, the nominal from which LBE takes places is a complement of another nominal, which assigns it genitive case.

(120) Crvene $_{\mathrm{i}}$ sam vidio [ $\mathrm{t}_{\mathrm{i}} \mathrm{kuće}$ ].

red am seen houses

'I saw red houses.'

(121) * ${ }^{*}$ rvenih $_{i} \quad$ sam vidio [NP2 vlasnike [NP1 $t_{i}$ kuća]]. red am seen owners houses

'I saw owners of red houses.'

For an account of the ungrammaticality of (121), the reader is referred to [11,13]. The precise reasons for the grammaticality of (121) need not concern us here. What matters is that, as $[11,13]$ show, the problem here arises with movement from NP1 to NP2 (there is no issue with movement out of NP1 per se (i.e., when the relevant NP is not dominated by another NP), otherwise even (120) would be unacceptable).

Bearing this in mind, the following data shed a crucial light on the timing of regular and sideward movement involved in ATB non-ATB.

(122) ?Crvenih ? $_{i} \quad$ i plavih $_{j}$ sam vidio [NP1 vlasnike [ConjP [NP $t_{i}$ kuća] i [NP $t_{j}$ red and blue am seen owners houses and automobila]]]

cars

'I saw owners of [red houses and blue cars].' 
(123) ${ }^{*}$ Crvenih $_{\mathrm{i}}$ i $\quad$ plavih $_{\mathrm{j}}$ sam vidio [ConjP [NP1 vlasnike [NP $\mathrm{t}_{\mathrm{i}}$ kuća] i [NP1 ljubitelje red and blue am seen owners houses and fans

[NP $t_{j}$ automobila]]] cars

'I saw [owners of red houses] and [fans of blue cars].'

There is a contrast between (122) and (123), which is particularly telling in light of the deep LBE effect from (121). The deep LBE effect is apparently still present in (123), but is voided in (122). What this means is that there is regular movement into NP1 in (123) but not in (122) (there are two NP1s, i.e., higher NPs, in (123) due to the level of coordination-cf. the translation of the examples). As discussed in $[11,13]$ and briefly noted above, adjectives are base-generated at the very edge of the nominal domain in SC (this is what makes LBE possible in SC). Any movement from this position will take the APs into NP1 in (123); this movement is precisely what [13] argues causes a problem in (121). Crucially, in (122), there is a phrase, namely ConjP, in between the lower nominal domain and the higher NP (i.e., NP1). The APs can then undergo movement from the base-position without moving into the higher nominal domain in (122), in contrast to (123), namely by moving to the edge of ConjP. $[3,4,62,63]$ provide independent evidence that movement to the edge of ConjP is in fact independently possible in SC. After undergoing this movement from their interpreted positions, the APs can then undergo sideward merger into the late-formed ConjP in (122). This late-formed ConjP should be inserted into the structure higher than the original ConjP (i.e., the indicated ConjP in (122)) given that, as [13] discusses, regular movement from the edge of the complement of N into the NP itself causes a locality violation in SC. Recall that, as discussed above, late-formed ConjP can be inserted into a phrase right above the original ConjP, which in this case is NP1. Since there is no regular movement from one NP domain into another there is then no locality violation.

The relevant derivations are mapped out below: simplifying what exactly happens here, I will simply assume that the complement of a noun in this context is a barrier (the exact situation is more complicated (see $[11,13]$ and discussion below), but this suffices for our purposes - the relevant phrase (i.e., the complement of the noun) is given in shadow bold red below). In (125), which corresponds to (123), regular movement (shown as movement of $\alpha$ ) crosses a barrier, which induces a locality effect (in fact, the same effect as in (121)). In (124), which corresponds to (122), regular movement does not cross a barrier-only sideward movement crosses a barrier, but sideward movement voids locality effects (crossing here is metaphorical, sideward movement voids islandhood because it actually does not involve crossing of the island boundary: $\alpha$ is merged with $\beta$ (forming a ConjP) in a separate derivational space, and then inserted into the position shown in (124)). ${ }^{45}$

(124) $\left[_{N P 1}[\alpha+\beta] N 1\left[_{\text {ConjP }} \alpha_{i}\left[_{N P} t_{i}\left(t_{i}\right.\right.\right.\right.$ in base-interpreted position of $\left.\alpha\right)$

$(125) *\left[\mathrm{NP} 1[\alpha+\beta]\left[\mathrm{NP} 1 \alpha_{\mathrm{i}} \mathrm{N} 1\right.\right.$ [NP $_{\mathrm{i}}$

The contrast between (122) and (123) was important in establishing the derivations outlined in (124), (125). Now, in these examples the nominal complement bears genitive case, which is the counterpart of accusative with verbs-it is the regular structural case that nouns assign to their complements. Just like some verbs assign special inherent cases to their complements, the same holds for some nouns. Importantly, [13] shows that while deep LBE out of genitive complements of nouns is unacceptable, as shown by (121), where the nominal complement is genitive, deep LBE out of complements of inherently case-marked complements of nouns is possible, as shown below. ${ }^{46}$

(126) Ekstremnomi je podržao otpor

extreme $_{\text {DAT }}$ is supported resistance

'He supported resistance to the extreme congress.'

\section{[ $\mathrm{t}_{\mathrm{i}}$ kongresu].} congress $\mathrm{DAT}$

As pointed out by a reviewer, this makes a prediction: the counterpart of (123) with an inherently Case-marked nominal complement should be better than (123). This is indeed the case. 
(127) ?Ekstremnom $_{i} \quad$ i $\quad$ privremenom $_{j}$

je podržao otpor extreme $_{\mathrm{DAT}}$ and temporaryDAT pomoć [ $\mathrm{t}_{\mathrm{j}}$ parlamentu]

help parliament $t_{D A T}$

is supported resistance
[ $t_{\mathrm{i}}$ kongresu] $\mathrm{i}$ congress $_{\mathrm{DAT}}$ and

The contrast between (123) and (127) quite strongly confirms the conclusions reached above regarding the contrast between (122) and (123). ${ }^{47}$

Notice also that when a noun is modified with two adjectives, double LBE distributed extraction is disallowed:

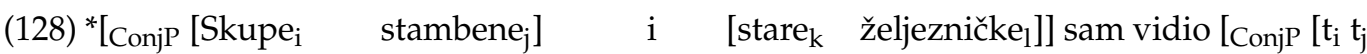
expensive $_{\text {fem }}$ residential $_{\text {fem }}$ and old masc $_{\text {railwaymasc am seen }}$

zgrade $\quad \mathrm{i} \quad\left[\mathrm{t}_{\mathrm{k}} \mathrm{t}_{\mathrm{l}}\right.$ mostove $]$

buildings $_{\text {fem }}$ and bridges masc

'I saw expensive residential buildings and old railway bridges.'

Importantly, even regular LBE is not possible in this context (see [12]).

(129) *Skupe $_{i} \quad$ stambene $_{j}$ je vidio [ $t_{i} t_{j}$ zgrade].

expensive residential is seen buildings

'He saw expensive residential buildings.'

There are, however, cases where double LBE is in principle. One such case, discussed in Section 2.1, is shown in (130). Importantly, distributed extraction coordination is also possible in this context, as (131) shows.

(130) $\mathrm{Onu}_{\mathrm{i}}$ staru $_{\mathrm{j}}$ je prodao [ $\left.\mathrm{t}_{\mathrm{i}} \mathrm{t}_{\mathrm{j}} \mathrm{kuću}\right]$.

that old is seen house

'He saw that old house.'

(131) $\left[\mathrm{Onu}_{\mathrm{i}}\right.$ staru $\left._{\mathrm{j}}\right] \mathrm{i} \quad\left[\mathrm{ovu}_{\mathrm{k}}\right.$ novu $\left._{1}\right]$ je prodao $\left[\mathrm{t}_{\mathrm{i}} \mathrm{t}_{\mathrm{j}} \mathrm{kućc}\right] \quad \mathrm{i}\left[\mathrm{t}_{\mathrm{k}} \mathrm{t}_{\mathrm{l}}\right.$ vikendicu]. that old and this new is sold house and weekend.house

All of this confirms the movability requirement on elements that participate in distributed extraction coordination: the relevant elements must be mobile, which indicates that they undergo regular movement before sideward merger.

Putting everything that we have seen above together, we can map out the derivation of non-ATB ATB constructions more generally. It is apparently not possible for the relevant elements to undergo sideward movement into late formed ConjP directly from the positions where they are interpreted. They have to undergo regular movement from that position, after which they can undergo sideward movement into the newly-formed ConjP. If a locality effect can be created right at the base-generated position, sideward movement will then not be able to obviate it (it would be taking place too late); but if the locality effect is created slightly higher than the base-generated position so that there is room for regular movement to take place before the locality effect kicks in, the locality effect gets obviated through sideward movement. Any locality effect higher up, i.e. higher than the point of insertion of the late-formed ConjP, which we have seen is still inserted close to the positions in which the relevant elements are base-generated, will still be in effect, due to the movement of the late-formed ConjP itself. All of this is mapped out in (132). (The brackets where a locality effect could in principle pop up due to regular, not sideward, movement crossing it are given in shadow bold red. For ease of exposition, I use a trace for the movement that precedes formation of the derivationally-formed ConjP, and a struck-out copy for the movement of the derivationally-formed ConjP itself. Two phrases are given between the final landing site and the original position of the movement of the derivationally-formed ConjP merely to indicate that this movement is generally longer than the movement that $\alpha$ alone undergoes, which is generally very short).

(132) $[\alpha+\beta]_{\mathrm{j}}\left[\mathrm{WP} \ldots\right.$ ZZP $_{\mathrm{Z}}[\alpha+\beta]_{\mathrm{j}}\left[\mathrm{YP} \alpha_{\mathrm{i}}\left[\mathrm{XP} \mathrm{t}_{\mathrm{i}}\right.\right.$

Regarding locality effects seen above, the locality effect in (123) arises due to the crossing of the redded XP between $\alpha_{i}$ and $t_{i}$ in (132), which means with movement of the 
element that will later participate in late coordination (122) crucially differs from (123) in that that step of movement in (122) does not cross a barrier; it essentially takes place below XP in (132) due to the presence of additional structure in (122). The locality effect in (82), on the other hand, arises due to the crossing of a redded phrase between $[\alpha+\beta]_{j}$ and $[\alpha+\beta]_{j}$ in (132), which means with movement of the late-formed coordination itself. The reconstruction effect in (83) also occurs on the path between $[\alpha+\beta]_{\mathrm{j}}$ and $[\alpha+\beta]_{\mathrm{j}}$. Regarding agreement effects, if agreement takes place below ZP in (132), which means below [ $\beta]_{j}$ (see (132)), it will involve agreement with an individual conjunct, i.e., $\alpha$. This is the case with (88) (and with SC A-N agreement). On the other hand, if it takes place above ZP, it will involve agreement with the whole ConjP, i.e., $[\alpha+\beta]$, which is the case with examples such as (90) and (94). The same holds for binding. If it takes place below YP, the individual conjuncts will function as binders. This is the case in (100), (102), (103), and (107). If it takes place above $\mathrm{YP}$, the whole coordination will function as the binder, which is the case in (99). ${ }^{48}$

Importantly, the facts discussed above indicate that islandhood/locality effects are selectively present with non-ATB ATB constructions. In most cases they are present, but in some cases they are voided. This could not be captured if we were to simply adopt Zhang's analysis, where the relevant elements undergo sideward merger into the late-formed ConjP straight from their interpreted position, with the late formed ConjP inserted in the final landing site-no locality effects should then be present at all (all the examples in (31), (64), (82), (114b), (117), (123), and (128) are thus problematic for this analysis). We also could not capture the state of affairs depicted above if the relevant elements were to undergo regular movement from their interpreted position all the way to their final landing site, with the late-formed ConjP formed there. For example, having in mind examples such as And then Ann left, where the complement of and is a non-coordinated CP, one could imagine an alternative to the sideward merger analysis on which the Conj head takes the whole $\mathrm{CP}$ as its complement. Assuming that the coordinated phrases have to move into ConjP, (6) could then be analyzed in terms of ConjP shells, as in [ConjP which book and [ConjP which magazine $\left.\left.t_{i}[C P . .].\right]\right] .{ }^{49}$ On such an analysis locality effects would never be obviated (122) is thus, problematic for this analysis)..$^{50}$ On the other hand, the selective presence of locality effects can be captured on an analysis which essentially combines the two accounts just noted, on which there is both regular movement and sideward movement involved in the derivation of non-ATB ATB constructions. We have seen that such an analysis can also capture agreement and binding effects found with non-ATB ATB constructions as well as the mobility requirement on the elements involved in non-ATB ATB and the ability of these elements to license parasitic gaps on their own.

\section{Conclusions}

This paper has provided additional evidence that it is possible to move different elements from conjuncts involved in the same coordination and that such constructions involve coordination formation in a non-base generated position, i.e., after movement (cf. [7]). It was shown that such constructions are also subject to the ATB requirement: although different elements are moving out of conjuncts movement still must take place out of each conjunct. This means that the traditional ATB requirement needs to be reformulated: it is not the case that the moving element must move out of each conjunct but simply that movement must take place out of each conjunct. It can be the same element that is moving out of each conjunct or different elements; the ATB requirement is satisfied as long as there is movement out of each conjunct (furthermore, the ATB requirement does not hold across ConjPs). Traditional ATB, where the same element moves out of more than one conjunct, and what I have referred to as non-ATB ATB, where different elements are moving out of the conjuncts, can in fact be mixed under extraction out of the same coordination, as expected if all that is needed is that there is movement out of each conjunct. Furthermore, mixed non-ATB ATB cases have the same ordering restrictions (regarding the order of the conjuncts) as pure non-ATB ATB cases. 
We have also seen that there is a restriction on non-ATB ATB, where different elements are moving from different conjuncts, in particular, non-ATB ATB requires coordination formation in the moved position. Additionally, head-movement cannot be involved in nonATB ATB, which in fact follows from the coordination-in-the-moved-position requirement if head coordination is disallowed, as [61] argued.

I have also discussed the precise timing of derivational coordination formation, concluding that the late-formed coordination is inserted into the structure very close to the phrase where the relevant elements are interpreted (under sideward merger analysis of distributed coordination; see Appendix A for the reason for this), not in the final position of the relevant elements (as in [7]). The relevant elements, however, first need to undergo regular movement from the positions where they are interpreted: they cannot undergo sideward merger into the derivationally-formed ConjP straight from the positions where they are interpreted: The derivation of non-ATB ATB constructions then involves both regular and sideward movement.

The derivationally-formed coordination is semantically expletive in that elements participating in such coordination are not interpreted as coordinated; as a result only the most neutral coordinator is used in such coordination (even when a different element is used in the lower position). The coordination in question has also been shown to cause agreement/semantics mismatches, which arise because a coordination that is not semantically interpreted participates in determining agreement. The presence of the coordinator in question was shown to be motivated by formal reasons (this is in fact what enables extraction of different elements from a single coordination).

Finally, the analyses and the coordination data discussed in this paper have been shown to have consequences for determining the proper analysis of a number of mechanisms and constructions, in particular subject-oriented anaphors, right node raising, tough-constructions, the source of agreement, and the more general issue of clausal structure. Regarding subject-oriented anaphors, non-ATB ATB constructions were shown to provide evidence against approaches where the element located in SpecTP and/or the element that undergoes Agree with T function as the binder for subject-oriented anaphors based on constructions where different elements fill SpecvP and SpecTP (in such cases, the latter undergoes agreement with $\mathrm{T}$ but the former binds subject-oriented anaphors).

Funding: This research received no external funding.

Acknowledgments: For helpful comments and suggestions, I thank anonymous reviewers, the audiences at University of Ljubljana and Slavic Linguistic Society 15 (organized by Indiana University), and the participants of my Fall 2021 seminar at the University of Connecticut, especially Akihiko Arano, Steven Franks, Adrian Stegovec, Sandra Stjepanović, and Ksenia Zanon.

Conflicts of Interest: The author declares no conflict of interest.

\section{Appendix A. On the Typology of Late Coordination Constructions}

Above we have seen a number of cases involving coordination formation in the moved position, i.e., after movement. All these cases also involve coordination in the lower position, i.e., they involve extraction out of a coordination. A question arises if late coordination formation is possible without coordination in the lower position, i.e., if the relevant movements do not take place out of a ConjP. [38] argue that it is. They consider constructions such as (133) and argue that cross-linguistically they can involve either larger (i.e., clausal) coordination where only the wh-phrase is realized in the first conjunct, which they argue is the case with English (133), or coordination of wh-phrases, which they argue is the case with Bulgarian (134).

(133) What and where did you eat?

(134) Koj and kakvo e kupil?

who and what is bought

'Who bought what?' 
They furthermore argue that wh\&wh coordinations such as (134) involve coordination formation after movement (analyzing it in fact in terms of sideward movement, following [7]). ${ }^{51}$ Thus, they observe that in English, it is not possible to have obligatory arguments in the coordination in question, as (135) shows. This is expected under the clausal coordination analysis, where (133) is treated as involving coordination of two clauses, what did you eat and where did you eat?

(135) *What and where did you buy?

The acceptability of (134) then indicates that we are dealing here with wh\&wh, rather than clausal coordination. ${ }^{52}$

Citko and Gračanin-Yuksek [38] also observe that coordinations such as (134) are not possible with wh-phrases in situ. In fact, it is quite generally not possible to coordinate a subject and an object of the same clause, which means that (134) cannot involve base coordination that would then undergo movement. In other words, the coordination here can only be formed after movement.

Note also that, like distributed coordinations, wh\&wh coordinations are sensitive to islandhood, as shown by Bulgarian (136), involving an adjunct island (note that Bulgarian does not show Comp-trace effects).

(136) *Koj i kakvo si jadosan zaštoto e kupil?

who and what are angry because is bought

'You are angry because who bought what?'

At any rate, if Citko and Gračanin-Yuksek's account of Bulgarian (134) is correct, such examples provide evidence that late coordination formation is not limited to constructions involving movement out of a coordination. Notice also that, like the derivationally-formed coordination discussed in the main text, the coordination discussed in the Appendix A is also not semantically interpreted. Thus, the interpretation of (134) is simply 'who bought what', there is no coordination of the wh-phrases in the interpretation of this construction. ${ }^{53}$ Not being interpreted, i.e., being semantically expletive in the relevant sense, can then be taken to be the hallmark of derivationally formed coordination (regardless of whether late coordination formation takes place out of a coordination or not). In other words, coordination can be formed during the derivation but if that happens it has no semantic import-only base-coordination is interpreted.

Notice, furthermore, that given that the structure instantiated by Bulgarian (134) is apparently not allowed in English, the availability of non-distributed wh\&wh coordinations, which, if [38] are right in their treatment of such coordinations involve late coordination formation without movement out of a coordination, should not be tied to the availability of constructions like (6) (which involve coordination in the lower position, i.e., late coordination formation out of a coordination), in a sense that the availability of the latter would imply the availability of the former (though SC happens to allow both, see (44) and the discussion below).

It should, however, be noted that the former (i.e., non-distributed late coordination) is not possible with the non-wh arguments in the SC example in (137) (the fronting in (137a) can in principle involve topicalization, focalization, or scrambling (see [100]), the construction is apparently ruled out regardless of which of these options is taken, in contrast to $(44)) .{ }^{54}$

(137) a. *Jovanu i knjigu daju.

Jovan $_{\text {DAT }}$ and book $_{\text {ACC }}$ they-are-giving

'They are giving Jovan a book.'

b. *Jovan i kuću kupuje.

Jovan $_{\mathrm{NOM}}$ and house ACC $_{\text {is-buying }}$

'Jovan is buying a house.' (SC) 
Postal-style distributed coordinations are not restricted in this way. Thus, they are possible with topicalization in (138) or even with A-movement, as discussed above (cf. (73), though there is crosslinguistic variation in this respect, as noted above). ${ }^{55}$

(138) Under the pillow and in the drawer Lulu put the diary and hid her letters, respectively [7], (p. 170)

Given that there clearly must be rather strong additional restrictions on non-distributed wh\&wh coordinations, which are not operative with Postal-style distributed coordinations, it is not out of question that the unavailability of the former in English (in contrast to the availability of the latter) is due to those additional restrictions, i.e., that we are not dealing with a deeper point of variation in this case, where English would allow late coordination formation only out of another coordination. (Recall that SC allows it regardless of whether late coordination formation takes place out of a coordination or not.) Rather, more construction-specific issues could be involved.

Citko and Gračanin-Yuksek [38] in fact tie the availability of wh\&wh coordination to the availability of multiple wh-fronting: since English does not have multiple whfronting it cannot then have the structure in question. However, it is not clear why multiple wh-fronting should be relevant here. Under Citko and Gračanin-Yuksek's analysis, the interrogative $\mathrm{C}$ in (134) has only one Spec, which is filled by ConjP.

There are additional reasons why the availability of (134) should not be tied to multiple wh-fronting. Thus, as another argument for the whwh (as opposed to clausal) coordination account of Bulgarian (134), [38] observe that such constructions show Superiority effects, i.e., strict ordering of coordinated wh-phrases. They argue that this would not be expected if (139) involves coordination of two clauses, where each clause has only one wh-phrase, which undergoes movement.

(139) a. Koj i kakvo e kupil?
who and what is bought
b. *Kakvo i koj e kupil?

Citko and Gračanin-Yuksek [38] argue that what is relevant here is that Bulgarian is a multiple wh-fronting language. Multiple wh-fronting languages differ regarding whether they show superiority effects under multiple wh-fronting (see for example [101,102]). Bulgarian does show such effects (see (140)), just as it does with wh\&wh coordinations (see (139)).

(140) a. Koj kakvo e kupil?

who what is bought

'Who bought what?'

b. *Kakvo koj e kupil?

In light of this, [38] tie the possibility of wh\&wh coordinations to multiple wh-fronting. The correlation is, however, rather difficult to maintain. Under the standard account, the superiority effect in (140) arises as a result of the interrogative $C$ attracting two wh-phrases, where these wh-phrases undergo separate wh-movements, occupying separate CP Specs. This is, however, not the case with (139) under [38]'s analysis, where the coordination of wh-phrases (i.e., ConjP dominating the wh-phrases) is merged into SpecCP-there are no two separate wh-movements or two CP Specs in (140). Furthermore, [38] also observe that some speakers of Bulgarian do allow free ordering of the coordinated wh-phrases in (139). On the other hand, there is no speaker variation regarding superiority effects with multiple wh-fronting.

Also relevant here is SC, which does not show matching in the ordering of wh-phrases in simple multiple wh-fronting constructions and wh\&wh coordinations. As noted above, multiple wh-fronting languages differ regarding whether or not they show superiority effects in examples such as (140). Thus, as discussed in [101,102], SC does not show Superiority effects in simple multiple wh-fronting constructions such as (141). 
(141) a. Ko šta kupuje?

who what is-buying

'Who is buying what?'

b. Šta ko kupuje?

However, SC does show ordering effects with wh-coordinations. ${ }^{56}$
(142) a. Ko i šta kupuje?
who and what is-buying
b. *Šta i ko kupuje?

Now, as discussed above, SC also allows larger coordinations involving wh-phrases, as indicated by the fact that additional material can be present within what appear to be wh\&wh conjuncts.

(143) Ko je i šta (je) kupio?

who is and what is bought

'Who bought what?'

The presence of the auxiliary clitic in (143) indicates that the first conjunct is actually a clause. Interestingly, such constructions, which unambiguously involve coordination that is larger than wh\&wh, do not show superiority effects. ${ }^{57}$

\section{(144) Šta je i ko (je) kupio?}

what is and who is bought

When there is nothing following the first wh-phrase there is a superiority effect, as shown by (142). ${ }^{58}$ On the other hand, when the clitic follows the first wh-phrase, which clearly shows that in such cases the first conjunct is larger than the wh-phrase itself, there is no superiority effect (see (143), (144)). These data indicate that when there is no additional material following the first wh-phrase we are indeed dealing with a wh\&wh coordination. ${ }^{59}$ These facts also indicate that there is no parallelism between Superiority effects in simple multiple wh-fronting constructions and wh\&wh constructions, given the contrast between (141) and (142) (more precisely, (141b) and (142b)), i.e., the parallelism shown by Bulgarian (140) and (139) is accidental.

In fact, there is reason to believe that whatever is going on with the ordering of wh-phrases in wh\&wh coordinations is different from superiority effects with multiple wh-fronting. As discussed in [102], quite generally when the superiority effect is found with multiple wh-fronting it holds only for the first and the second wh-phrase; beyond that the ordering of the wh-phrases is free. This is shown by Bulgarian (145): when only two objects undergo wh-movement, the indirect object must precede the direct object, a superiority effect given that the former is higher than the latter prior to wh-movement. However, when a higher wh-phrase is present, the ordering of the indirect and direct object is free (the nominative must be first in (145c), (145d) as well as (146c) and (147) below). The same point is illustrated by SC (146), where the superiority effect also holds only for the first and the second wh-phrase (see [102] for discussion of the superiority effect in (146a), (146b). ${ }^{60}$

(145) a. Kogo kakvo e pital Ivan? whom what is asked Ivan

'Who did Ivan ask what?'

b. ?*Kakvo kogo e pital Ivan?

c. Koj kogo kakvo e pital?

who whom what is asked

'Who asked whom what?'

d. Koj kakvo kogo e pital? [102], (p. 366) 
(146) a. ?Ima kome kako da pomogne.

has whom how part helps

'(S)he has someone to help somehow.'

b. *Ima kako kome da pomogne.

c. ?Ima ko kako kome da pomogne.

has who how whom part helps

'There is someone who can somehow help somebody' [102], (p. 367).

Recall now that SC shows an ordering effect with wh\&wh coordinations involving two wh-phrases. However, the ordering effect here extends to all wh-phrases: when there are more than two wh-phrases there is strict ordering between all of them, as shown by (147).

(147) a. Ko komei šta daje?

who whom and what is-giving

'Who is giving what to whom

b. ${ }^{*}$ Ko šta i kome daje?

who what and whom is-giving

The data discussed above indicate that the ordering effect found with wh\&wh coordinations is independent of Superiority (more precisely, what is considered to be superiority effects associated with multiple wh-fronting).

That the ordering effect found in late coordination formation constructions, which holds in all types of such constructions discussed in this paper (see below), should be dissociated from ordering/superiority-style effects found with multiple wh-fronting is confirmed quite strongly by certain data regarding multiple left-branch extraction discussed by [105]. Although SC generally does not show superiority effects with simple multiple wh-fronting constructions (there are contexts where SC does show such effects, see [102]), Stjepanović shows that if multiple wh-fronting involves multiple left-branch extraction it does show ordering effects, as illustrated below. (An intervening element is added in (149) to make sure that there is left branch extraction from the subject. [105] shows that several factors are relevant in such cases, including agreement patterns between the extracted left-branch and the remnant.)

$(148) *{ }^{*} \mathrm{iji}_{\mathrm{i}} \quad \mathrm{kakva}_{\mathrm{j}}$ whose what-kind-of

[ $t_{i}$ otac] kupuje [ $t_{j}$ kola]?

father is-buying car

'Whose father is buying what kind of a car?'

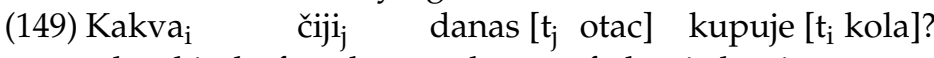

what-kind-of whose today father is-buying car

'Whose father is buying what kind of a car today?'

Importantly, wh\&wh coordinations do not match multiple wh-fronting constructions in this respect.

(150) C $_{\mathrm{ijj}} \mathrm{i}_{\mathrm{i}} \mathrm{i} \quad \mathrm{kakva}_{\mathrm{j}} \quad$ [ $\mathrm{t}_{\mathrm{i}}$ otac] kupuje [ $\mathrm{t}_{\mathrm{j}}$ kola]? whose and what-kind-of father is-buying car 'Whose father is buying what kind of a car?

(151) ${ }^{*} \mathrm{Kakva}_{\mathrm{i}}$ i čiji $\mathrm{i}_{\mathrm{j}}$ danas [ $\mathrm{t}_{\mathrm{j}}$ otac] kupuje [ $\mathrm{t}_{\mathrm{i}}$ kola]? what-kind-of and whose today father is-buying car

'Whose father is buying what kind of a car today?'

As noted above, [38] take the superiority parallelism between Bulgarian (140) and (139) to indicate that the availability of multiple wh-fronting underlines the availability of wh\&wh coordinations (which, recall, involve late coordination formation). The fact that, as shown above, wh\&wh coordinations do not track multiple wh-fronting with respect to Superiority suggests that the two should be divorced. There should then be no connection between multiple wh-fronting and the possibility of late coordination formation (which underlines the possibility of Postal-style distributed coordination - this is desirable given the possibility of the latter in English). 
At any rate, there is crosslinguistic variation regarding non-distributed wh\&wh coordinations, whose availability should not be tied to either the availability of multiple wh-fronting or Postal-style distributed coordination in the language.

While the issues discussed in this appendix merit a much more extensive scrutiny than they could be given in this appendix, whose scope is rather limited, what we are seeing here is that languages differ with respect to how they behave regarding the relevant properties of coordinate constructions. The point of the above discussion was merely to outline some of the possible crosslinguistic variation in the relevant domain, as well as to highlight the need for more extensive crosslinguistic investigations of the relevant properties of coordinations (recall that languages also differ regarding whether they allow conjunct extraction, see for example SC (77), which is unacceptable in English). Hopefully, such investigations will reveal correlations between the properties of coordination investigated in this paper and other properties, which should help determine in a more principled way the factors that are behind the phenomena (and the variation with respect to these phenomena) discussed in this paper.

I will close this appendix with a note on the ordering effect. Postal-style distributed extractions pattern with wh\&wh coordinations in the relevant respect. As discussed in Section 3, there is an ordering effect with Postal-style distributed extractions-the order of the conjuncts within the newly formed ConjP must match the order of the conjuncts from which extraction takes place in the original Conj $\mathrm{P}$-which in the cases involving three conjuncts holds for all conjuncts, as shown by SC (152), which gives the only possibility for the distributed interpretation of the extracted adjectives. The same holds for English distributed coordinations, as shown by (153).

(152) Crveni $_{i}$, bijeli $i_{j}$ šareni ${ }_{k}$ meni [ $t_{i}$ sako], [ $t_{j}$ kaput] $i \quad$ [ $t_{k}$ šešir] smetaju. red white and colorful me DAT jacket coat and hat bother

'The red jacket, white coat, and colorful hat bother me.'

(153) Which book $_{i}$, which magazine ${ }_{j}$, and which painting ${ }_{k}$ did Mary [buy $t_{i}$ ], [read $t_{j}$ ], and [sell $t_{k}$ ] respectively?

Non-distributed wh\&wh coordinations and Postal-style distributed coordinations thus pattern together, and differ from MWF regarding the ordering effect.

If the ordering effect in the two constructions is to be captured in a unified manner, the ordering effect with Postal-style distributed coordinations cannot be due to a matching effect between two coordinations (as suggested briefly in Section 3) since with wh\&wh coordinations there is no lower ConjP. I would therefore like to suggest an alternative. In particular, I suggest that derivational coordination formation needs to occur as early as possible. More precisely, the relevant element needs to merge with the non-base coordinator as soon as it is eligible for such merger. (142), repeated in (154), would then be derived as in (155) (using English words for ease of exposition):

(154) a. Ko i šta kupuje?

who and what buys

b. *Šta i ko kupuje?

(155) a. [vp buys what]

b. [Conjp and what] (sideward merger)

c. [vP who buys what]

d. [ConjP who and what] (sideward merger)

The element that enters the structure first then has to undergo sideward merger with the coordinator first, as shown in (155b) (i.e., what merges with and before who does). The result of this is that the order of elements in the derivationally formed ConjP will correspond to the order of these elements prior to derivational coordination formation, with ordering imposed on all conjuncts, not just on one relevant element (as it is with Superiority). ${ }^{61}$

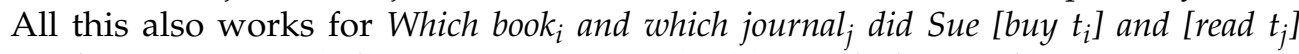
respectively; given the cycle/bottom up structure building, which journal has to merge with and, the head of the derivationally formed ConjP, before which book (since the conjunct 
that dominates it is integrated into the structure by merging with the base coordinator and first). ${ }^{62}$

The above suggestion also enables us to deduce the contiguity requirement on mixed ATB and non-ATB ATB cases. To illustrate it again, in (156), (157) regular ATB can hold between contiguous conjuncts, it cannot hold between the first and the third conjunct, skipping the second conjunct.

(156) ?How many cakes and how many letters did Mary bake, read, and mail respectively? (157) ${ }^{*}$ How many letters ${ }_{i}$ and how many cakes $j$ did Mary read $t_{i}$, bake $t_{j}$, and address $\mathrm{t}_{\mathrm{i}}$ respectively?

Given the earliness requirement on late coordination formation, how many letters must merge both before and after how many cakes into the late formed ConjP in (157) (more precisely, it has to be sideward merged into it after and address. is formed; there can be no regular ATB after that step, i.e., out of the late-formed coordination, since late-formed coordinations are opaque for merger out of them, see Section 6). The early sideward merger requirement (i.e., the requirement to form the derivationally formed ConjP as soon as possible) thus deduces the strict ordering requirement as well as the contiguity requirement on derivationally formed ConjPs.

Recall now that the derivationally formed ConjP has to be inserted into the structure very close to the step of regular movement that the relevant elements need to undergo. This can be interpreted as indicating that the derivationally formed ConjP has to be inserted into the structure as early as possible. From this perspective, this earliness requirement can be looked at as part of a more general earliness requirement on derivational ConjP formation: such ConjPs must be formed as soon as possible and inserted into the structure as soon as possible.

\section{Notes}

(4) also involves a ban on extraction of conjuncts, which will not be examined in this work (the ban on extraction out of conjuncts and the ban on extraction of conjuncts have anyway ban argued to be independent conditions, see e.g., [2-6]).

2 There are some differences across speakers regarding the most natural prosody of such constructions. The judgments given below reflect the most natural prosody for the speakers in question (not all speakers accept such coordinations in the first place). Zhang argues the higher ConjP is formed through sideward movement, proposed in [8]. The analysis is discussed in Section 7. Some speakers do not find a difference between $(9 a)$ and $(9 b)$, while some have a slight preference for either (9a) or (9b) (hence (?) in the examples).

5 Regarding examples such as (i), where wh-movement takes place out of the second and third, and head-movement out of the first conjunct, they will be discussed in Section 5, where we will see that a problem independent of the ATB requirement arises here. (i) ${ }^{*}\left[\right.$ Which newspaper ${ }_{i}$ and which magazine $e_{j}$ did ${ }_{k}$ [Mary $t_{k}$ write a book], [John may buy $t_{i}$ ], and [Bill will read $t_{j}$ ] respectively.

6 One of my informants actually rejects (21). Importantly, the informant also disallows (20) (the informants who accept (21) also accept (20)), which confirms that non-ATB ATB and regular ATB indeed behave in the same way with respect to the parallelism requirement in question.

7 These authors argue that constructions such as (22) involve extraction of the AP out of the NP. There are two alternative analyses: remnant movement of the NP which contains only the AP $([17,18])$ and full NP movement with scattered deletion, where the $\mathrm{NP}$ is deleted in the highest copy and the AP in the lower copy ([19]). There are a number of arguments in the literature for the left-branch extraction analysis, which is adoped here; see e.g., [12,15,20-23]. The reader is also referred to [24] for discussion of the CSC regarding SC, where it is shown that (1) is operative in SC.

8 All the judgments below are given only for the distributive reading, indicated in the translations of (23), (24) (and with traces when they are given in the structures below).

9 A referee observes that, as expected, (i), where there is no adjective at the edge of the conjunct that is not involved in ATB, is also unacceptable:
(i) ${ }^{*}$ Crvena ${ }_{i}$ i bijeli $j_{j}$ meni $\left[t_{i}\right.$ suknja], [ $t_{j}$ kaputi] i [košulje] smetaju.

red and white me coat and shirts bother

10 What may matter here is the following: [25] proposes that the first conjunct determines the category of the whole coordination (which essentially means that the coordination itself does not inherently have it; note that Chomsky's proposal is stated somewhat differently, in terms of labeling), and a number of authors (e.g., $[24,26,27]$ ) have argued that the ATB requirement is related to the coordination-of-likes requirement (see [26,28-32], among others, on this requirement). An intuitive idea here is that when 
the first conjunct, which is supposed to determine the category of a coordination, is itself a coordination, the category of the higher coordination is undetermined-this then voids the ATB requirement, which is tied to category specification (this is what is relevant to the coordination-of-likes requirement). This makes a prediction, which is borne out: if the order of the conjuncts in (29) is switched, the category of the coordination will be determined since the first conjunct is not a coordination; this then activates the ATB requirement, ruling out (i) because it does not have a gap in each conjunct (namely the first conjunct).
(i) * Crvena
bijeli $_{j}$ mene [ConjP1 [šareni
šešir] i ([ConjP2 $t_{i}$ suknja i
$t_{j}$ kaput])] iritiraju.
red and white me colorful hat skirt and coat irritate

See also [33] regarding islandhood of English non-ATB ATB. One of their examples, involving an inner island effect, is given in

(i) (see this work for additional examples, but see also [7]).

(i) * $\left.\left[[\text { How loudly }]_{i} \text { and [how softly }\right]_{j}\right]$ didn't you say [[that John had spoken $\left.t_{i}\right]$ and [that Peter had replied $\left.\left.t_{j}\right]\right]$ ?

Speakers differ regarding the preferred position for respectively here, hence both options are given in the examples.

This could also be seen as a maximize ATB effect, similar to [35]'s Max Elide (see [36] for a Max ATB-style proposal). It may be worth noting that a similar effect is found with parasitic gaps, which are often treated similarly to ATB (see e.g., [8], who treats both in terms of sideward movement), as the following data from [34], (p. 547) show: it is not possible to skip a potential parasitic gap site in (i).

(i) a. Who did you praise $e$ to the sky [after criticizing $e$ ] [in order to surprise $e$ ]?

b. Who did you praise $e$ to the sky [after criticizing $e$ ] [in order to surprise him]?

c. *Who did you praise $e$ to the sky [after criticizing him] [in order to surprise $e$ ]?

The contrast between (33) and (39) in fact parallels the contrast between (ib) and (ic).

Another case of the maximize ATB effect may be provided by the contrast between (33) and (ii).

(ii) *Crvena ${ }_{i}$, crvena $_{j} \mathrm{i} \quad$ bijeli $_{k}$ meni [ $t_{i}$ suknja], [ $t_{j}$ košulja] $i \quad$ [ $t_{k}$ kaput] smetaju. red red and white me $e_{\text {DAT }}$ skirt, shirt and coat bother

It is also not clear how the interpretation would work on the clausal ellipsis analysis, given that 'white' modifies only the second conjunct (i.e., "dress") in (24). Note that the following is not the relevant interpretation for (46) (the example is marginally acceptable on that interpretation):

(i) Crvene su menisuknje i haljinesmetale i bijele su meni suknje i haljine smetale.

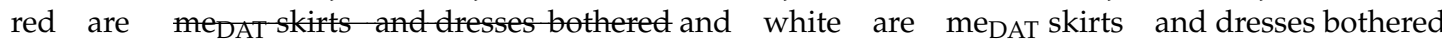

'Red skirts and dresses bothered me and white skirts and dresses bothered me.'

There is a potential prosodic issue in (49). For some speakers, under the most natural prosody the fronted adjectives bear focal stress and are followed by a pause. This causes an issue regarding clitic placement. There is variation across speakers whether under certain conditions a clitic can follow a sentence internal pause (see [39-43]). I ignore here speakers for whom there needs to be a pause following the fronted adjectives and who disallow clitic placement after such a pause (pronominal clitics are quite generally disallowed in that case, hence they are avoided below in this context).

On the relevant reading, onu is not a separate nominal in (51), (52) (demonstratives can be separate nominals, as in I like this) but modifies kuću, just like staru does (there is only one nominal on this reading, 'that old house'). Below, where possible different gender will be used for the demonstrative and the adjective to control for this.

It is worth noting here that NP ellipsis that strands demonstratives and adjectives is also possible in SC, see [45]. One might try to treat (24) this way. The ungrammaticality of (53), however, provides evidence not only against the clausal ellipsis analysis, but also against the NP ellipsis analysis.

As with other languages, there is some controversy regarding whether Japanese floating quantifiers should be analyzed in terms of [46]-style stranding, or as adverbials generated outside of the relevant nominals (for relevant discussion of Japanese, see [47-54], among others). The controversy is actually not relevant to the current discussion; the point made in this section holds regardless of which of these two analyses is adopted. In this respect, it should be noted that [55] argues for Sportiche's analysis on the basis of examples such as (55). In [56], however, the author points out that (55) can be analyzed in accordance with the adverbial analysis if what is coordinated in (55) is VPs, with the verb undergoing string vacuous V-to-T-to-C movement, with each numeral adjoined to a VP conjunct (this is necessary under the semantic implementations of the adverbial analysis, as in [54] and [57], where the individual numerals, not a ConjP containing the numerals, need to be composed with the VP). Given this, regardless of which of these two analyses of floating quantifiers is adopted, examples such as (56) below involve non-ATB ATB out of a coordination, which is what is important for our purposes. (The two analyses would differ regarding what is coordinated in (55), (56), nominals or VPs, but that difference is not relevant for our purposes-under both analyses examples such as (56) would involve non-ATB ATB out of a coordination, the relevant nominals would move either from a coordinated quantifier+nominal complex or from inside of coordinated VPs).

For independent reasons, it is not possible to test the possibility of mixing non-ATB ATB and regular ATB here (regular ATB is independently not possible in this case since the ATBed NP would have to be associated with two different numbers).

20 Notice that such cases argue against an analysis on which the presence of two conjunctions in distributed coordinations would somehow be a result of pronounciation of two copies of the same conjunction. It should be noted that [58] suggests that sosite is a clausal coordinator (for relevant discussion, see also [56]). However, my informants allow examples like (i) on the interpretation where John and Mary arrived together, in fact tomoni 'together' can be added to (i) (the argument regarding sosite constructions 
holds for the speakers who allow sosite to function as a non-clausal coordinator, in addition to functioning as a clausal coordinator). Note also that the case marker is optional in the first conjunct in both (i) and (60). Under Ishii's clausal coordinator analysis, the first conjunct would actually be a full clause, with ellipsis taking place in it. It is then expected that the relevant clause should be fine in isolation, with or without the case particle. However, for my informants, the relevant example is degraded without the case particle, as in (ii). (The same argument extends to (60). Note that this does not rule out the clausal coordinator option for sosite).

(i) John(-ga) sosite Mary-ga tootyakushita.

John-NOM and Mary-NOM arrived

'John and Mary arrived.'

(ii) John(??-ga) tootyakushita.

John-NOM arrived

Note also that, as in SC, nothing can be inserted between the elements undergoing non-ATB ATB in the Japanese construction under consideration.

Wh-island violations with D-linked wh-phrases are actually very weak; (65) is way worse than (i).

(i) ?Which president do you wonder why John reads articles about?

Examples similar to (68), involving extraction of different elements from conjuncts without coordination in the higher position, were discussed in $[7,36,59]$ for Russian, Polish, as well as SC, and noted to be unacceptable. Note that (68) is unacceptable regardless of the placement of the clitic su. (69) gives the only possible clitic placement here (this also holds for (70) and (71), see Section 3 for relevant discussion).

Notice that wh left-branch extraction, as well as multiple left-branch extraction, are in principle possible in SC (see [44,60] and Section 3).

Such crosslinguistic differences underscore the need for more in depth crosslinguistic investigations of the distributed extraction coordination construction, one of the main goals of this paper in fact being to spur such investigations. Note that examples such as (74) indicate that we cannot simply have allowing or dissalowing distributed extraction coordination as the point of crosslinguistic variation since the same language can allow it with some but not other movements. In fact, the variation can also concern the coordination from which it takes place; thus, Japanese allows it out of -to coordinations (see Section 4) but disallows it out of sosite coordinations: In contrast to (55), (i) disallows non-ATB ATB regardless of whether the higher coordination involves -to or sosite (see Section 4 for relevant options; what may actually be relevant here is also when different options for what sosite may coordinate are allowed, see Fn. 4).
(i) John-ga [vp [pp yaoya-kara]
[mikan-o 3-ko] sosite
[banana-o 5-hon] katta.
John-NOM vegetable.store-from orange-ACC 3-CL and
banana-ACC 5-CL bought

'John bought [ 3 oranges and 5 bananas] from a vegetable store.'

One of his arguments concerns the impossibility of coordinating clitics, as in the French example in (i).

(i) *Je le et la vois souvent.

I him and her see often (French)

Sideward merger might be a more appropriate term (if movement is taken to involve a c-command relation between the relevant positions); at any rate I will use the terms interchangeably below.

This does not mean that phases in general are islands; phases have the potential to induce locality violations, which can then capture islandhood.

One issue these works were concerned with is the well-known impossibility of reconstruction into the second conjunct with regular ATB (see $[8,65,66]$ for relevant discussion under the null operator movement and the sideward movement analysis respectively).

Chomsky's approach to the PIC differs in this respect from $[69,70]$, where the edge of the edge of phase XP is not at the edge of XP. I am adopting Chomsky's approach to the PIC in this respect. (Notice also that [24] argues that movement to the edge of individual conjuncts is quite generally allowed). It should be noted that it is beyond the scope of this paper to examine the nature of the ATB requirement itself. As noted in Fn. 10, several works have argued that the ATB requirement actually follows from the coordination-of-likes requirement, namely, [24,26,27]. Under the implementation of this approach in [24], extraction out of the first conjunct is allowed in certain cases even where there are no gaps in other conjuncts (which is in part due to the accessibility of the edge of the first conjunct, see [24] for other factors involved). Any gap in a non-initial conjunct, on the other hand, obligatorily "activates" the ATB requirement, forcing the presence of a gap in each conjunct.

We will see below some cases where the relevant elements move to the edge of ConjP. Given that only the outmost edge of a phase is actually available for movement out of a phase, as argued extensively in [44], the problem discussed in the text would still arise there (though the trace voiding mechanism discussed in [44] should not be applicable with ConjP, possibly because of its island status). 
Under the Spec-Head agreement analysis, there would be no need for XP since the late-formed ConjP could be inserted directly into SpecTP, with agreement taking place between T and the ConjP in SpecTP in a Spec-Head relation. (Certain constructions discussed below would, however, require the presence of XP even under this analysis, see Fn. 48.) Plural agreement is not morphologically realized here in English, but it is in SC, where the verb is plural in (93). Such examples were noted in $[2,7,78,79]$.

In other words, the interpretation of the conjuncts is 'John was hunting lions' and 'Mary was freightened by snakes'. Still, the agreement in (94) is plural. Note that the agreement/interpretation mismatch confirms the semantic expletiveness of derivationally formed coordination. The mismatch arises because a coordination that is not semantically interpreted participates in determining agreement.

This would be AgrsP of early minimalism ([80] in fact uses examples like John travels to Rome tomorrow and will travel to Tokyo on Monday to argue for a return to Split Infl (see also [81,82], among others).

38 The same point can be made with (i) (from [83], modified to include a simplified derivation from the current approach).

(i) *Every Sunday, $\left[J_{0 h} n_{i} \text { and Mary }\right]_{k}\left[v P t_{i}\right.$ see each other $\left.r_{k}\right]$ and $\left[{ }_{v P} t_{j}\right.$ kiss each other $\left.{ }_{k}\right]$ respectively.

Note that a late formed coordination can be itself modified. This is what happens in (ii), where the late-formed coordination, Sue and Karen, is modified with an appositive.

(ii) Sue and Karen, who love each other very much, sing and dance respectively [84].

Regarding the PF deletion analysis, typically (see e.g., [61]), what is deleted under this analysis, applied to (112), is the object in the first conjunct, with the object in the second conjunct staying in situ, which seems to leave no room for insertion of the late formed ConjP in (112). [95], however, shows that the element in the second conjunct can undergo rightward heavy NP shift within that conjunct. The late formed ConjP can then be inserted in that position. Another case of distributed extraction coordination interacting with right node raising is provided by (i).

(i) George and Martha respectively denounced and were denounced by the governor [7].

(i) can be derived similarly to (94) (cf. (95)-(98)), as shown in (ii), with T agreeing with the late-formed coordination within each conjunct prior to this coordination undergoing regular ATB movement.

(ii) [YP [ConjP George and Martha] [Conjp [TP T [XP [ Conjp George and Martha] [ ${ }_{\mathrm{vP}}$ George denounced] and [TP were-T

[XP [ Conp George and Martha] [vp denounced Martha]

The partial structure in (ii) raises a question: how is the 'governor' interpreted in the object position of the first conjunct? The answer is provided by right node raising, which is possible in this context:

(ii) John denounced and Martha was denounced by the governor.

Above I have briefly aluded to an alternative analysis on which agreement is established in a Spec-Head relation. While for reasons of space I did not discuss this analysis, this conclusion also extends to the Spec-Head agreement analysis (although this analysis comes with different structural assumptions, see Fn. 33).

A small adjustment will in fact be made below to accommodate an additional step in the derivation of distributed coordinations discussed below. (I have assumed above that there is no vP in passives although there is some controversy regarding this issue. At any rate, what is important here is simply that the late-formed ConjP is inserted very close to the base positions of the relevant elements.)

In this respect, note that Slovenian speakers generally disallow regular adjectival LBE and they also disallow it with distributed extraction coordinations of the kind discussed for SC here, which confirms that the mobility of the relevant elements matters. There is actually some speaker variation in this respect in British English, see [96].

The first-projection-locality-requirement on late-formed ConjP insertion discussed above should now be adjusted to take into consideration this short regular movement (it would be the first projection above the phrase where this short regular movement lands (or even within that phrase in some cases-I return to this issue below). At any rate, what is important is that the late-formed ConjP is inserted very close to the landing site of this movement. It should be noted that there is one exception to the mobility requirement, which concerns right node raising. Right node raising is known to be able to affect elements that are otherwise immobile, see e.g., [95]. The same holds when right node raising involves distributed extraction. It then seems that we are dealing here with a right node raising-specific issue, which is independent of the mobility requirement on distributed extractions discussed in the text:

(i) a. John likes cheap, and Mary likes expensive, swimming suites.

b. John is asking when, and Mary is asking why, Peter is leaving.

(ii) a. John likes cheap, and Mary likes expensive, trousers and dresses respectively.

b. John is asking when, and Mary is asking why, Peter is leaving and Amy is late respectively.

Slightly more complicated are cases like (34), which involve a mixture of non-ATB ATB and traditional ATB.

(i) Crvena $a_{i}$ bijeli meni [ $t_{i}$ suknja], [ $t_{i}$ košulja] $\mathrm{i} \quad$ [ $t_{j}$ kaput] smetaju. red and white me $e_{\mathrm{DAT}}$ skirt, shirt and coat bother

Consider (i) under [8]'s sideward merger analysis of traditional ATB. Under this analysis and the current analysis of distributed coordinations, (i) is derived as follows: "white" is merged with "coat"; "red" is merged with "shirt" and then undergoes sideward merger with "skirt" (this is regular ATB). Both "red" and "white" then move to the edge of the lower ConjP, after 
which derivational coordination formation takes place, with "red" and "white" undergoing sideward merger that forms what I have called late-formed ConjP (note that only derivational ConjP formation is subject to the not-directly-from-the-interpretedposition restriction).

Bošković [13] argues that in inherent case configurations, there is actually a PP-like projection between the two NPs, which means that the higher noun does not directly take NP as its complement in (126) (and (127) below), in contrast to (121) and (123) (see [13] for discussion why this matters).

As noted by Sandra Stjepanović (p.c.), examples such as (127) can also help us control for an interfering factor regarding (30). In (i), the adjective can modify both conjoined nouns, which means (ib) does not necessarily involve ATB movement of the adjective; it can also involve regular ATB of a single adjective with (ia) as its input (note this is not possible in three conjuct examples (on the true coordination non-list reading), as with the SC counterpart of white coat, red skirt, and dress). Given this, an issue arises: how do we know that (30) does not involve adjectival ATB from the first conjunct, instead of one adjective being adjoined to the ConjP, taking scope over both Ns?

(i) a. Svidaju mi se crvene suknje i haljine. please me self red skirts and dresses

b. Crvene mi se svidjaju suknje i haljine.

'I like red skirts and (red) dresses.'

Deep left-branch extraction with inherently Case-marked NPs controls for this interferring factor: due to the extra layer of embedding, AP adjunction to ConjP that conjoins the relevant nouns is not possible in (ii) (kongresu and parlementu are not conjoined), which means that the possibility of one adjective taking scope over, and modifying, two conjoined nouns prior to extraction is not an option here. (iii) must then involve regular ATB.

(ii) Ovogodišnjem $\mathrm{O}_{\mathrm{i}}$ je podrŽao [otpor [ $\mathrm{t}_{\mathrm{i}}$ kongresu]] $\mathrm{i}$ [pomoć [ $\mathrm{t}_{\mathrm{i}}$ parlamentu]]. this-year's is supported resistance congress DAT $_{\text {and }}$ help parliament $t_{\text {DAT }}$ 'He supported resistance to this year's congress and helping this year's parliament.'

(iii) Ovogodišnjem $\mathrm{i}_{\mathrm{i}}$ je podrŽao [otpor $\mathrm{t}_{\mathrm{i}} \quad$ kongresu] [ $\mathrm{t}_{\mathrm{i}}$ pomoć parlamentu] i prijetnje $\left[\mathrm{t}_{\mathrm{i}}\right.$ predsjedniku] this-year's is supported resistance congress $_{\mathrm{DAT}}$ help parliament ${ }_{\mathrm{DAT}}$ and threats president $\mathrm{DAT}_{\mathrm{DAT}}$ 'He supported resistance to this year's congress, helping this year's parliament, and threats to this year's President.'When regular ATB dependency is blocked, as in (iv) (in (iii) all relevant elements, the adjective and the nouns, are masculine; in (iv) 'government' is feminine, blocking ATB), we get an ungrammatical construction.

(iv) *Ovogodišnjem $i$ je podržao [otpor [ $t_{i}$ kongresu]] [pomoć [ $t_{i}$ parlamentu]] i [prijetnje (novoj) vladi]

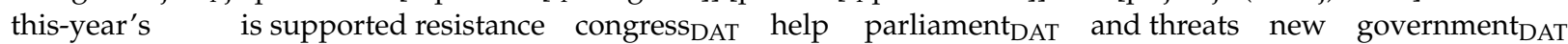
Importantly, like (30), (v), where there is no possibility of the adjective modifying both nouns prior to extraction (the nouns are not conjoined), is also acceptable with the relevant prosodic pattern (like (30), (v) has an additional coordinator).

(v) Ovogodišnjem $\mathrm{i}_{\mathrm{i}}$ je podržao ([otpor [ $\mathrm{t}_{\mathrm{i}}$ kongresu]] $\mathrm{i} \quad$ [pomoć [ $\mathrm{t}_{\mathrm{i}}$ parlamentu] $)$ i [prijetnje (novoj) this-year's is supported resistance congress DAT $_{\text {and help parliament }}$ at and threats new vladi]. governnment $t_{\mathrm{DAT}}$

The derivations of examples (90) and (94) given above can be easily adjusted to accommodate the movement from the interpreted position prior to sideward merger into the late-formed ConjP. Regarding (94) (cf. the derivation in (95)-(98)), one possibility is that there is a projection between XP and VP, with the relevant elements moving to that projection within their respective conjuncts prior to sideward merger (i.e., prior to step (96)). There is, however, another possibility which does not require an additional projection: the individual conjuncts, John and Mary, undergo separate movements to Specifiers of XP in (97) prior to the late-formed ConjP insertion, with this ConjP inserted into the higher Specifier of XP (note that the Spec-Head Agreement analysis, briefly discussed in Fn. 33, would also require a projection between VP and TP to accommodate the regular movement that precedes sideward merger into the late-formed ConjP). As for (90) (cf. the derivation in (92)), given that it is not possible for different elements to undergo movement out of a ConjP (so sideward merger is needed to obviate the locality effect, as discussed above), a dog and a rooster would move separately to the edge of ConjP if movement to the edge of ConjP is also allowed in English, or, if this is not possible in English, (90) would involve coordination on a slightly higher level (than vP in (92a)), with $a$ dog and $a$ rooster moving to the edge of the projection that undergoes coordination prior to undergoing sideward merger into the late-formed ConjP. Further research is needed to tease apart the options in question. If there are more than two conjuncts, the higher ConjP can have multiple Specs, or there can be additional ConjP shells.

There are other issues that would arise on this analysis. Under this analysis, it is not clear how the relevant elements could trigger agreement together (cf. (90), (94), (105), (106), (111)) or function as binders together (cf. (99)) (assuming the ConjP in question is on top of the structure; we might actually then expect the coordination in question to be a strictly matrix phenomenon, which it is not (cf. Peter inquired which book and which magazine John bought and Mary sold respectively). Notice also that the relevant elements can be clefted together (cf. it is this book and that song that Mary wrote and Tom sang respectively). This indicates that they are a consitutent, which is not the case under the alternative analysis outlined in the text.

51 I will use the term (non-distributed) wh\&wh coordination to refer to constructions which involve coordination of wh-phrases (not a larger constituent) and where the wh-phrases are not extracted out of a coordination. For ease of exposition, to differentiate such cases from examples like (6), where there is a lower ConjP, I will refer to the latter as (Postal-style) distributed coordinations. 
Furthermore, [37] notes that wh-DP external material can occur within the relevant ConjP in English, as shown by (i). Nothing of that sort is possible in Bulgarian. (Note that SC allows both obligatory arguments and DP-external material in the coordinations in question, as shown by (44), (45), the reason for this being that SC allows both whwh and larger clausal coordination, see [38] (I am simplifying their discussion here) and the discussion below.)

(i) What did Peter and why did Peter eat? [37]

It would be interesting to see whether such coordination is possible in rare languages that disallow multiple questions (e.g., Italian, which disallows constructions such as who bought what); whether or not such languages would allow late coordination formation of wh-phrases might shed light on the reason for the unacceptability of multiple questions in such languages.

I discuss restrictions on non-distributed late coordination in SC in work in progress, where I show that this kind of coordination, without coordination in a lower position, is actually not completely restricted to wh-phrases/wh-movement.

In SC, Postal-style wh-movement distributed coordinations are actually more restricted than in English. One issue could be that SC does not have a real counterpart of respectively that is used in such cases in English. What is happening in SC is that (possibly due to the lack of 'respectively' or the possibility of wh\&wh coordinations), the non-distributed reading on which the coordination of wh-phrases undergoes ATB-movement from each object position is the only reading in the counterpart of (6) in SC.

(i) [Koju knjigu i koji magazin $]_{i}$ je Jovan kupio $t_{i}$ i Ivan prodao $t_{i}$ ?

which book and which magazine is Jovan bought and Ivan sold

'Which book and which magazine did John buy and Ivan sell?'

However, when such non-distributed ATB-movement parse is not possible, as in (69), Postal-style distributed coordination is available with wh-phrases in SC. It is also marginally available in constructions more similar to (i) where the pragmatics increases the saliency of the distributed reading (with a different coordinator though; $a$ is a clausal coordinator, which does not coordinate nominals).

(ii) ?Koliko jela i koliko pisama je Marija napravila a Ivan napisao?

how-many dishes and how-many letters is Maria made and Ivan wrote

'How many dishes and how many letters did Maria make and Ivan write?'

(142b) improves if there is a pause following the first wh-phrase, which is not necessary in (141b). For the relevance of this prosodic pattern, which I put aside in the text, see Fn. 60.

There may be a null subject in the first conjunct and a null object in the second conjunct here. SC is a pro-drop language so the former is not surprising. On null objects in similar constructions, see [103] and references therein (for other perspectives on these issues, see $[37,38])$.

The same holds if the clitic follows the coordinated wh-phrases.
(i) a. Ko i šta je kupio?
b. *Šta i ko je kupio?

who and what is bought

This in itself is quite interesting. We may be dealing here with an economy of representation effect (see [104] and references therein): when both a smaller and a larger structure are in principle available for $X$, if there is no evidence for the larger structure $X$ is analyzed in terms of the smaller structure. (We would not necessarily expect to find this effect in all languages of this sort since the effect would hold only in an all-else-being-equal scenario, which is not always the case; e.g., lexical properties of elements that are elided on the larger structure option could block the effect—see [92].) There may, however, be another factor at work here. Recall that, as noted in Fn. 57, (142b) improves if there is a pause following the first wh-phrase. It may then be that wh\&wh and clausal coordination are associated with two distinct prosodic patterns in the cases where nothing intervenes between the coordinated wh-phrases, the prosodic pattern with a pause following the first wh-phrase reflecting clausal coordination structure. This prosodic pattern is forced by a superiority violation, which is not allowed in the wh\&wh derivation. It should be noted that according to Citko and Gračanin-Yuksek, there is no superiority effect in wh\&wh coordinations in Croatian. The speakers I have consulted, all of which come from Bosnia, do show a superiority effect here (in fact all the data discussed above come from the Bosnian variety of what I have referred to as SC). It is not out of question that there is no real variation here, and that Citko and Gračanin-Yuksek were checking the prosodic pattern associated with clausal coordination. (This may also be behind what they report as speaker variation in the ordering effect in Bulgarian; while Citko and Gračanin-Yuksek do not give relevant Croatian data they do give superiority-violating examples from Russian. However, it turns out superiority violations in Russian are possible only under the prosodic pattern associated with clausal coordination). At any rate, while the issue under consideration is quite interesting, it goes beyond the scope of this paper, which focuses on distributed coordinations. As discussed in [102], SC shows superiority effects in certain contexts; one such context is the one given in (146).

61 (i) may indicate that the wh-phrase that enters the structure first may not need to merge with the coordinator immediately, but simply before the other wh-phrase enters the structure. This is so if kakva kola 'what-kind-of car' in (i) moves in front of the verb before kakva is sideward-merged into the late formed ConjP. Alternatively, it is possible that kakva sideward merges into the late formed ConjP before the object moves in front of the verb in (i). (i) would then involve a remnant-like fronting of the object (the remnant being created by sideward merger). 

(i) $\check{C}_{\mathrm{iji}} \quad$ i $\quad$ kakva whose and
$\mathrm{kakva}_{\mathrm{j}}$
[ $t_{i}$ otac] [ $t_{j}$ kola] kupuje?

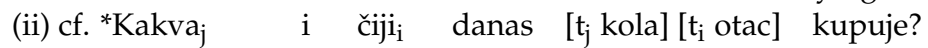
what-kind-of
father car is-buying
what-kind-of and whose today car father is-buying

While I have been assuming that sideward merger into ConjP takes place after the short movement step, it could even take place before it-in the latter case the original copy would both sideward-merge and undergo the short movement step; note the lack of a c-command relation, even the ConjP does not c-command anything before integration into the structure.

\section{References}

1. Ross, J.R. Constraints on Variables in Syntax. Ph.D. Thesis, MIT, Cambridge, MA, USA, 1967.

2. Postal, P.M. Three Investigations of Extraction; MIT Press: Cambridge, MA, USA, 1998.

3. Stjepanović, S. Left Branch Extraction and the Coordinate Structure Constraint. In Proceedings of the NELS 44: 44th Annual Meeting of the North East Linguistic Society, Storrs, CT, USA, 18-20 October 2013; Iyer, J., Kusmer, L., Eds.; Graduate Linguistic Student Association: Amherst, MA, USA, 2014; Volume 2, pp. 157-170.

4. Oda, H. Two Types of the Coordinate Structure Constraint and Rescue by PF Deletion. In Proceedings of the NELS 47: 47th Annual Meeting of the North East Linguistic Society, Amherst, MA, USA, 14-16 October 2016; Lamont, A., Tetzloff, K., Eds.; Graduate Linguistic Student Association, University of Massachusetts: Amherst, MA, USA, 2017; Volume 2, pp. 343-356.

5. Oda, H. Decomposing and Deducing the Coordinate Structure Constraint. Linguist. Rev. in press.

6. Grosu, A. On the Nonunitary Nature of the Coordinate Structure Constraint. Linguist. Inq. 1973, 4, 88-92.

7. Zhang, N. Coordination in Syntax; Cambridge University Press: Cambridge, MA, USA, 2010.

8. Nunes, J. Linearization of Chains and Sideward Movement; MIT Press: Cambridge, MA, USA, 2004.

9. Franks, S.L. On Parallelism in Across-the-Board Dependencies. Linguist. Inq. 1993, 24, 509-529.

10. Franks, S. Parameters of Slavic Morphosyntax; Oxford University Press: New York, NY, USA, 1995.

11. Corver, N. On deriving certain left branch extraction symmetries: A case study in parametric syntax. In Proceedings of the 22nd Conference of the North-East Linguistic Society, Newark, DE, USA, October 1991; Broderick, K., Ed.; GLSA: Amherst, MA, USA, 1992; pp. 67-84.

12. Bošković, Ž. On the Locality of Left Branch Extraction and the Structure of NP. Stud. Linguist. 2005, 59, 1-45. [CrossRef]

13. Bošković, Ž. Phases beyond Clauses. In The Nominal Structure in Slavic and Beyond; Schürcks, L., Giannakidou, A., Etxeberria, U., Eds.; Mouton de Gruyter: Berlin, Germany, 2013; pp. 75-128.

14. Despić, M. Syntax in the Absence of Determiner Phrase. Ph.D. Thesis, University of Connecticut, Storrs, CT, USA, 2011.

15. Talić, A. From A to N and Back: Functional and Bare Projections in the Domain of N and A. Ph.D. Thesis, University of Connecticut, Storrs, CT, USA, 2017.

16. Talić, A. Upward P-Cliticization, Accent Shift, and Extraction out of PP. Nat. Lang. Linguist. Theory 2019, 37, 1103-1143. [CrossRef]

17. Franks, S.; Progovac, L. On the Placement of Serbo-Croatian Clitics. In Indiana Linguistic Studies 7, Proceedings of the 9th Biennial Conference on Balkan and South Slavic Linguistics, Literature, and Folklore, Indiana University Bloomington, Bloomington, IN, USA, 7-9 April 1994; Indiana University Linguistic Club: Bloomington, IN, USA, 1994; Volume 7, pp. 69-78.

18. Abels, K. Successive Cyclicity, Anti-Locality, and Adposition Stranding. Ph.D. Thesis, University of Connecticut, Storrs, CT, USA, 2003.

19. Fanselow, G.; Ćavar, D. Distributed Deletion. In Theoretical Approaches to Universals; Alexiadou, A., Ed.; John Benjamins Publishing Company: Amsterdam, The Netherlands, 2002; pp. 65-107.

20. Stjepanović, S. Left Branch Extraction in Multiple Wh-Questions: A Surprise for Question Interpretation. In Proceedings of the Formal Approaches to Slavic Linguistics (FASL) 18, Ithaca, NY, USA, 15-17 May 2009; Browne, W., Cooper, A., Fisher, A., Kesici, E., Predolac, N., Zec, D., Eds.; Michigan Slavic Publications: Ann Arbor, MI, USA, 2010; pp. 502-517.

21. Stjepanović, S. Differential Object Marking in Serbo-Croatian: Evidence from Left Branch Extraction in Negative Concord Constructions; Bailyn, J., Dunbar, E., Kronrod, Y., LaTerza, C., Eds.; Michigan Slavic Publications: Ann Arbor, MI, USA, 2012 ; pp. 99-115.

22. Talić, A. Extraordinary Complement Extraction: PP-Complements and Inherently Case-Marked Nominal Complements. Stud. Pol. Linguist. 2013, 8, 127-150. [CrossRef]

23. Despić, M. Some Issues in the Theory of Nominal Domain: Reflexive Possessives, Left Branch Extraction and Quantifier Raising; Handout from Talk at Mie University, 2015.

24. Bošković, Ž. On the Coordinate Structure Constraint and Labeling. In Proceedings of the West Coast Conference on Formal Linguistics 36, Los Angeles, CA, USA, 20-22 April 2018; Cascadilla Press: Sommervile, MA, USA, 2019; pp. 71-80.

25. Chomsky, N. Problems of Projection. Lingua 2013, 130, 33-49. [CrossRef]

26. Sag, I.A.; Gazdar, G.; Wasow, T.; Weisler, S. Coordination and How to Distinguish Categories. Nat. Lang. Linguist. Theory 1985, 3 , 117-171. [CrossRef]

27. Takahashi, D. Minimality of Movement. Ph.D. Thesis, University of Connecticut, Storrs, CT, USA, 1994.

28. Chomsky, N. Syntactic Structures; Mouton: The Hague, The Netherlands, 1957.

29. Schachter, P. Constraints on Coordination. Language 1977, 53, 86-103. [CrossRef]

30. Williams, E. Across-the-Board Rule Application. Linguist. Inq. 1978, 9, 31-43. [CrossRef]

31. Bowers, J. The Syntax of Predication. Linguist. Inq. 1993, 24, 591-656. [CrossRef] 
32. Beavers, J.; Sag, I.A. Coordinate Ellipsis and Apparent Non-Constituent Coordination. In Proceedings of the 11th International Conference on Head-Driven Phrase Structure Grammar, Center for Computational Linguistics, Katholieke Universiteit Leuven, Leuven, Belgium, 3-6 August 2004; Müller, S., Ed.; CSLI Publications: Stanford, CA, USA, 2004; pp. 48-69.

33. de Vos, M.; Vicente, L. Coordination under Right Node Raising. In Proceedings of the WCCFL 24, Burnaby, BC, Canada, 18-20 March 2005; Alderete, J., Han, C., Kochetov, A., Eds.; Cascadilla Proceedings Project: Somerville, MA, USA, 2005 ; pp. 97-104.

34. Nissenbaum, J. Investigations of Covert Phrase Movement. Ph.D. Thesis, MIT, Cambridge, MA, USA, 2000.

35. Merchant, J. The Syntax of Silence: Sluicing, Islands, and the Theory of Ellipsis; Oxford University Press: Oxford, UK, 2001.

36. Citko, B. ATB Wh-Questions and the Nature of Merge. In Proceedings of the NELS 33, Cambridge, MA, USA, 8-10 November 2002; Kadowaki, M., Kawahara, S., Eds.; GLSA: Amherst, MA, USA, 2003; pp. 87-102.

37. Gračanin-Yuksek, M. About Sharing. Ph.D. Thesis, MIT, Cambridge, MA, USA, 2007.

38. Citko, B.; Gračanin-Yuksek, M. Towards a New Typology of Coordinated Wh-Questions. J. Linguist. 2013, 49, 1-32. [CrossRef]

39. Bošković, Ž. On the Nature of the Syntax-Phonology Interface: Cliticization and Related Phenomena; Elsevier Science: Amsterdam, The Netherlands, 2001.

40. Bennett, D. Word-Order Change in Progress: The Case of Slovene and Serbo-Croat and Its Relevance for Germanic. J. Linguist. 1987, 23, 269-287. [CrossRef]

41. Percus, O. The Captious Clitic: Problems in Serbo-Croatian Clitic Placement; Ms., MIT: Cambridge, MA, USA, 1993.

42. Browne, W. Serbo-Croatian Enclitics for English-Speaking Learners. In Contrastive Analysis of English and Serbo-Croatian; Filipovic, R., Ed.; Institute of Linguistics: Zagreb, Croatia, 1975; pp. 105-134.

43. Schütze, C. Serbo-Croatian Second Position Clitic Placement and the Phonology-Syntax Interface. In MIT Working Papers in Linguistics 21: Papers on Phonology and Morphology; Carnie, A., Harley, H., Bures, T., Eds.; MITWPL: Cambridge, MA, USA, 1994; pp. 373-473.

44. Bošković, Ž. Getting Really Edgy: On the Edge of the Edge. Linguist. Inq. 2016, 47, 1-33. [CrossRef]

45. Bošković, Ž. Adjectival Escapades. In Proceedings of the Formal Approaches to Slavic Linguistics 21, Bloomington, IN, USA, 11-13 May 2012; Franks, S., Dickinson, M., Fowler, G., Whitcombe, M., Zanon, K., Eds.; Michigan Slavic Publications: Ann Arbor, MI, USA, 2013; pp. 1-25.

46. Sportiche, D. A Theory of Floating Quantifiers and Its Corollaries for Constituent Structure. Linguist. Inq. 1988, 19, 425-449.

47. Miyagawa, S. Structure and Case Marking in Japanese; Academic Press: New York, NY, USA, 1989.

48. Kawashima, R. The Structure of Extended Nominal Phrases: The Scrambling of Numerals, Approximate Numerals, and Quantifiers in Japanese. J. East Asian Ling. 1998, 7, 1-26. [CrossRef]

49. Ishii, Y. A Note on Floating Quantifiers in Japanese. In Linguistics: In Search of the Human Mind: A Festschrift for Kazuko Inoue; Muraki, M., Iwamoto, E., Eds.; Kaitakusha: Tokyo, Japan, 1999; pp. 236-267.

50. Miyagawa, S.; Arikawa, K. Locality in Syntax and Floating Numeral Quantifiers. Linguist. Inq. 2007, 38, 645-670. [CrossRef]

51. Watanabe, A. Functional Projections of Nominals in Japanese: Syntax of Classifiers. Nat. Lang. Linguist. Theory 2006, 24, 241-306. [CrossRef]

52. Watanabe, A. The Structure of DP. In The Oxford Handbook of Japanese Linguistics; Miyagawa, S., Saito, M., Eds.; Oxford University Press: Oxford, UK, 2008; pp. 513-540.

53. Fitzpatrick, J.M. Syntactic and Semantic Routes to Floating Quantification. Ph.D. Thesis, MIT, Cambridge, MA, USA, 2006.

54. Nakanishi, K. Domains of Measurement: Formal Properties of Non-Split/Split Quantifier Constructions. Ph.D. Thesis, University of Pennsylvania, Philadelphia, PA, USA, 2004.

55. Kamio, A. Suuryooshi-No Shintakusu [Syntax of Numeral Quantifiers]. Gengo 1977, 6, 83-91.

56. Koizumi, M. Phrase Structure in Minimalist Syntax. Ph.D. Thesis, MIT, Cambridge, MA, USA, 1995.

57. Brisson, C.M. Distributivity, Maximality, and Floating Quantifiers. Ph.D. Thesis, New Brunswick Rutgers, The State University of New Jersey, New Brunswick, NJ, USA, 1998.

58. Ishii, T. On Coordinated Multiple Wh-Questions. In Proceedings of the Formal Approaches to Japanese Linguistics 7, Tokyo, Japan, 27-29 June 2014; Kawahara, S., Igarashi, M., Eds.; MITPWL: Cambridge, MA, USA, 2014; pp. 89-100.

59. Kasai, H. Two Notes on ATB Movement. Lang. Linguist. 2004, 5, 167-188.

60. Stjepanović, S. Deriving Multiple Left Branch Extraction. In Proceedings of the Formal Approaches to Slavic Linguistics 25, Ithaca, NY, USA, 13-15 May 2016; Browne, W., Despic, M., Enzinna, N., Lemos, S.H., Karlin, R., Zec, D., Eds.; Michigan Slavic Publications: Ann Arbor, MI, USA, 2018.

61. Kayne, R. The Antisymmetry of Syntax; MIT Press: Cambridge, MA, USA, 1994.

62. Stjepanović, S. Extraction out of Coordinate Structure Conjuncts. In Proceedings of the Formal Approaches to Slavic Linguistics 26, Champaign, IL, USA, 19-21 May 2017; Ionin, T., McDonald, J., Eds.; Michigan Slavic Publications: Ann Arbor, MI, USA, 2020; pp. 380-397.

63. Bošković, Ž. On the Coordinate Structure Constraint, Islandhood, Phases, and Rescue by PF Deletion. In A festschrift for Steven Franks; Fowler, G., Lavine, J., Feldstein, R., Eds.; Slavica Publishers: Bloomington, IN, USA, in press.

64. Chomsky, N. Barriers; MIT Press: Cambridge, MA, USA, 1986.

65. Munn, A. A Null Operator Analysis of ATB Gaps. Linguist. Rev. 1992, 9, 1-26. [CrossRef]

66. Munn, A. Topics in the Syntax and Semantics of Coordinate Structures. Ph.D. Thesis, University of Maryland, College Park, MD, USA, 1993. 
67. Chomsky, N. Minimalist Inquiries: The Framework. In Step by Step: Essays on Minimalist Syntax in Honor of Howard Lasnik; Martin, R., Michaels, D., Uriagereka, J., Eds.; MIT Press: Cambridge, MA, USA, 2000; pp. 89-155.

68. Chomsky, N. Derivation by Phase. In Ken Hale: A Life in Language; Kenstowicz, M., Ed.; MIT Press: Cambridge, MA, USA, 2001; pp. 1-52.

69. Bošković, Ž. From the Complex NP Constraint to Everything: On Deep Extractions across Categories. Linguist. Rev. 2015, 32, 603-669. [CrossRef]

70. Hiraiwa, K. Dimensions of Symmetry in Syntax: Agreement and Clausal Architecture. Ph.D. Thesis, MIT, Cambridge, MA, USA, 2005.

71. Chomsky, N. The Minimalist Program; MIT Press: Cambridge, MA, USA, 1995.

72. Cinque, G. Adverbs and Funcitonal Heads: A Cross-Linguistic Perspective; Oxford University Press: New York, NY, USA, 1999.

73. Collins, C. A Smuggling Approach to the Passive in English. Syntax 2005, 8, 81-120. [CrossRef]

74. Merchant, J. Voice and Ellipsis. Linguist. Inq. 2013, 44, 77-108. [CrossRef]

75. De Swart, H. Aspect Shift and Coercion. Nat. Lang. Linguist. Theory 1998, 16, 347-385. [CrossRef]

76. Ramchand, G.; Svenonius, P. Deriving the Functional Hierarchy. Lang. Sci. 2014, 46, 152-174. [CrossRef]

77. Tenny, C. The Aspectual Interface Hypothesis. In Lexical Matters; Sag, I.A., Szabolcsi, A., Eds.; Center for the Study of Language and Information: Stanford, CA, USA, 1992; pp. 1-27.

78. Dougherty, R.C. Recent Studies on Language Universals. Found. Lang. 1970, 6, 505-561.

79. McCawley, J.D. The Syntactic Phenomena of English, 2nd ed.; The University of Chicago Press: Chicago, IL, USA, 1998.

80. Bošković, Ž. On the Coordinate Structure Constraint, Across-the-Board-Movement, Phases, and Labeling. In Recent Developments in Phase Theory; van Craenenbroeck, J., Pots, C., Temmerman, T., Eds.; Mouton de Gruyter: Berlin, Germany, 2020 ; pp. 133-182.

81. Cardinaletti, A. Toward a Cartography of Subject Positions. In The Structure of CP and IP: The Cartography of Syntactic Structures; Rizzi, L., Ed.; Oxford University Press: Oxford, UK, 2004; Volume 2, pp. 115-165.

82. Rizzi, L. On the Form of Chains: Criterial Positions and ECP Effects. In Wh-Movement: Moving On; Cheng, L.L.-S., Corver, N., Eds.; MIT Press: Cambridge, MA, USA, 2006; pp. 97-133.

83. Goodall, G. Parallel Structures in Syntax: Coordination, Causatives, and Restructuring; Cambridge University Press: Cambridge, MA, USA, 1987.

84. Chaves, R.P. Conjunction, Cumulation and Respectively Readings. J. Linguist. 2012, 48, 297-344. [CrossRef]

85. Pica, P. On the Nature of the Reflexivization Cycle. In Proceedings of the North East Linguistic Society 17, Cambridge, MA, USA, November 1986; GLSA: Amherst, MA, USA, 1987; pp. 483-500.

86. Reuland, E. Anaphora and Language Design; MIT Press: Cambridge, MA, USA, 2011.

87. Antonenko, A. Feature-Based Binding and Phase Theory. Ph.D. Thesis, Stony Brook University, New York, NY, USA, 2012.

88. Lasnik, H. Verbal Morphology: Syntactic Structures Meets the Minimalist Program. In Evolution and Revolution in Linguistic Theory: Essays in Honor of Carlos Otero; Campos, H., Kempchinsky, P., Eds.; Georgetown University Press: Georgetown, WA, USA, 1995; pp. 251-275.

89. Stjepanović, S. What Do Second Position Cliticization, Scrambling and Multiple Wh-Fronting Have in Common? Ph.D. Thesis, University of Connecticut, Storrs, CT, USA, 1999.

90. Johnson, K. Object Positions. Nat. Lang. Linguist. Theory 1991, 9, 577-636. [CrossRef]

91. Lasnik, H. A Note on Pseudogapping. MIT Work. Pap. Linguist. 1995, 27, 143-163.

92. Bošković, Ž. The Syntax of Nonfinite Complementation: An Economy Approach; MIT Press: Cambridge, MA, USA, 1997.

93. Abels, K. Right Node Raising: Ellipsis or Across the Board Movement? In Proceedings of the NELS 34, Stony Brook, NY, USA, 7-9 November 2003; Moulton, K., Wolf, M., Eds.; GLSA: Amherst, MA, USA, 2004; pp. 45-59.

94. Bošković, Ž. On Smuggling, the Freezing Ban, Labels and Tough-Constructions. In Smuggling in Syntax; Belletti, A., Collins, C., Eds.; Oxford University Press: Oxford, UK, 2020; pp. 53-95.

95. Bošković, Ž. Two Notes on Right Node Raising. Univ. Conn. Work. Pap. Linguist. 2004, 12, 13-24.

96. Holmberg, A.; Sheehan, M.; van der Wal, J. Movement from the Double Object Construction Is Not Fully Symmetrical. Linguist. Inq. 2019, 50, 677-721. [CrossRef]

97. Douglas, J.A. The Syntactic Structures of Relativisation. Ph.D. Thesis, University of Cambridge, Cambridge, MA, USA, 2016.

98. Hornstein, N.; Weinberg, A. Case Theory and Preposition Stranding. Linguist. Inq. 1981, 12, 55-91. [CrossRef]

99. Stjepanović, S. In Search for the Correlate of a Preposition Missing under Sluicing. In Proceedings of the Formal Approaches to Slavic Linguistics 22: The McMaster Meeting, Hamilton, ON, Canada, 3-5 May 2013; Chapman, C., Kit, O., Kučerová, I., Eds.; Michigan Slavic Publications: Ann Arbor, MI, USA, 2014; pp. 418-439.

100. Bošković, Ž. Topicalization, Focalization, Lexical Insertion, and Scrambling. Linguist. Inq. 2004, 35, 613-638. [CrossRef]

101. Rudin, C. On Multiple Questions and Multiple WH Fronting. Nat. Lang. Linguist. Theory 1988, 6, 445-501. [CrossRef]

102. Bošković, Ž. On Multiple Wh-Fronting. Linguist. Inq. 2002, 33, 351-383. [CrossRef]

103. Zanon, K. On Hybrid Coordination and Quantifier Raising in Russian. Ph.D. Thesis, Indiana University, Bloomington, IN, USA, 2015 
104. Bošković, Ž. Last Resort with Move and Agree in Derivations and Representations. In The Oxford Handbook of Linguistic Minimalism; Boeckx, C., Ed.; Oxford University Press: Oxford, UK, 2011; pp. 327-353.

105. Stjepanović, S. On Multiple Source Left-Branch Extraction. In Proceedings of the 29th Annual Meeting of Formal Approaches to Slavic Linguistics (FASL 29), University of Washington, Seattle, WA, USA, 8-10 May 2020. 